Review Article

\title{
Adverse Health Effects of Betel Quid and the Risk of Oral and Pharyngeal Cancers
}

\author{
Ping-Ho Chen, ${ }^{1,2,3,4}$ Qaisar Mahmood, ${ }^{5}$ Gian Luigi Mariottini, ${ }^{6}$ \\ Tai-An Chiang, ${ }^{7}$ and Ka-Wo Lee ${ }^{8,9}$ \\ ${ }^{1}$ School of Dentistry, College of Dental Medicine, Kaohsiung Medical University, No. 100 Shih-Chuan 1st Road, \\ Kaohsiung 80708, Taiwan \\ ${ }^{2}$ Department of Medical Research, Kaohsiung Medical University Hospital, No. 100 Shih-Chuan 1st Road, Kaohsiung 80708, Taiwan \\ ${ }^{3}$ Cancer Center, Kaohsiung Medical University Hospital, Kaohsiung Medical University, No. 100 Shih-Chuan 1st Road, \\ Kaohsiung 80708, Taiwan \\ ${ }^{4}$ Institute of Biomedical Sciences, National Sun Yat-sen University, No. 70 Lienhai Road, Kaohsiung 80424, Taiwan \\ ${ }^{5}$ Department of Environmental Sciences, COMSATS Institute of Information Technology, Abbottabad, Pakistan \\ ${ }^{6}$ Department of Earth, Environment and Life Sciences (DISTAV), University of Genova, Viale Benedetto XV 5, 16132 Genova, Italy \\ ${ }^{7}$ College of Human Science and Technology, Chung Hwa University of Medical Technology, No. 89, Wenhwa 1st St., Rende Shiang, \\ Tainan 71703, Taiwan \\ ${ }^{8}$ Department of Otolaryngology, Kaohsiung Medical University Hospital, No. 100 Shih-Chuan 1st Road, Kaohsiung 807, Taiwan \\ ${ }^{9}$ Department of Otolaryngology, College of Medicine, Kaohsiung Medical University, No. 100 Shih-Chuan 1st Road, \\ Kaohsiung 80708, Taiwan
}

Correspondence should be addressed to Ka-Wo Lee; kawolee@kmu.edu.tw

Received 12 March 2017; Revised 1 May 2017; Accepted 18 May 2017; Published 11 December 2017

Academic Editor: Takashi Saku

Copyright (C) 2017 Ping-Ho Chen et al. This is an open access article distributed under the Creative Commons Attribution License, which permits unrestricted use, distribution, and reproduction in any medium, provided the original work is properly cited.

Global reports estimate 600 million betel quid (BQ) chewers. BQ chewing has been demonstrated not only to be a risk factor for cancers of the oral cavity and pharynx and oral potentially malignant disorders (OPMD) but also to cause other cancers and adverse health effects. Herein, we summarized the international comparison data to aid in the understanding of the close relationship between the prevalence of BQ chewing, the occurrence of oral and pharyngeal cancers, and adverse health effects. Potential biomarkers of BQ carcinogens, such as areca nut, alkaloids, and 3-methylnitrosaminopropionitrile (MNPN), are closely associated with human health toxicology. Molecular mechanisms or pathways involving autophagy, hypoxia, COX-2, NF- $\kappa \mathrm{B}$ activity, and stemness are known to be induced by BQ ingredients and are very closely related to the carcinogenesis of cancers of oral and pharynx. BQ abuse-related monoamine oxidase (MAO) gene was associated with the occurrence and progress of oral and pharyngeal cancers. In summary, our review article provides important insights into the potential roles of environmental BQ (specific alkaloid biomarkers and nitrosamine products MNPN) and genetic factors (MAO) and offers a basis for studies aiming to reduce or eliminate BQ-related OPMD and oral/pharyngeal cancer incidences in the future.

\section{Introduction}

Betel quid (BQ) is an environmental carcinogen with human health toxicology. In Asia and among diverse migrant populations in western countries, BQ use is an emerging healthrelated issue. In the world, BQ chewing is the fourth most common psychoactive habit after the usage of tobacco, alcohol, and caffeine beverages [1]. It is a masticatory mixture containing various components, such as areca nut (AN), slaked lime (calcium hydroxide), betel leaf, and locally varied flavorings [2]. In many countries, integration of tobacco, another known carcinogen, into the $\mathrm{BQ}$ is practiced [2]. It has been reported that 600 million chewers worldwide (approximately 10\% of the population) use certain variety of BQ, mainly in South East and South Asia, in the IndoPakistan subcontinent, in mainland China (Hunan Province 
and Hainan Special Administrative Region), in Taiwan, and on the South Pacific region (such as Palau, Papua New Guinea, and Solomon Islands) [3, 4]. Moreover, BQ chewing is also common among Asian immigrants to the Africa, Australia, United States, and United Kingdom [2, 3, 5].

Users chew BQ for its pharmacological effects, such as well-being sensations and euphoria, heightened alertness, and focused attention, as well as diminished hunger and improved digestion [6, 7]. BQ is not only a psychostimulant and addictive substance [8] but also a carcinogen [9]. The International Agency for Research on Cancer (IARC) disclosed that BQ substances, with and without tobacco additives, have been classified as group I carcinogens in humans, and elevated risks were noted for oral $[10,11]$ and pharyngeal [12] cancers and oral potentially malignant disorders (OPMD) [13, 14]. In addition, $\mathrm{AN}$ is also a group I carcinogen for humans [9]. In animal experiments, there is strong evidence suggesting that BQ can induce the occurrence of cancers of oral and pharynx [9].

Habitual BQ chewing has been especially related to the occurrence and development of OPMD [13, 14, 18] and oral/pharyngeal cancers $[10,11,19]$. In many areas, tobaccofree $\mathrm{BQ}$, commonly in conjunction with the usage of tobacco and/or alcohol, induces early cancer occurrence for specific upper aerodigestive tract cancers and affects the incidence pattern of tumor site of these neoplasms [20]. In addition, epidemiological investigations have revealed that prolonged BQ use confers an increased risk of esophagus [21], hepatocellular carcinoma (HCC) [22-24], liver cirrhosis [25], metabolic syndromes $[26,27]$, likely contributing to type 2 diabetes mellitus (DM) [28], high blood pressure [29], cardiovascular disease [30, 31], heart disease in women [32], chronic kidney disease [33], and adverse effects on mortality from cancer and from all causes [30, 34, 35]. BQ addiction has also been linked to anemia [36], adverse pregnancy outcomes [37, 38], and acute severe asthma $[39,40]$. Increasingly, BQ usage is recognized for its association with multidimensional health effects (Table 1).

\section{BQ Usage Multidimensional Health Effects (Table 1)}

To date, BQ chewing is associated with malignant and premalignant lesions of the oral cavity as well as other malignancies. In a case-control study, the highest risk of calculated incidence for oral cancer among BQ chewers with both smoking and drinking habits was 123-fold (95\% CI 17.1-880.5) compared with abstainers [10]. This study also indicated that $\mathrm{BQ}$ chewing alone was an independent risk factor related to the oral cancer occurrence [10]. A further study suggested that BQ use was an important risk factor of both oral submucosal fibrosis (OSF) and oral leukoplakia [18] and smoking had a modifying effect in oral leukoplakia development [18]. In Taiwan, a case-control study of pharyngeal and laryngeal cancers demonstrated that BQ chewing habit was a prominent risk factor for the occurrence of pharyngeal cancer (adjusted odds ratio $[\mathrm{aOR}]=7.7 ; 95 \% \mathrm{CI}$ $=4.1-15.0$ ) but not for laryngeal cancer, providing the first insight into BQ chewing effects on other digestive tract sites [12]. Investigations into esophageal cancer in one hospitalbased study of 165 cases and 255 controls showed that those who chewed AN with betel inflorescence ( $\mathrm{aOR}=4.2 ; 95 \% \mathrm{CI}$ $=1.4-16.0$ ) and chewers with a habit of swallowing BQ juice $(\mathrm{aOR}=3.3$; 95\% CI $=1.3-9.3$ ) had a significantly elevated risk of esophageal cancer [21].

Another malignancy linked to BQ chewing is hepatocellular carcinoma (HCC). In case-control studies, BQ chewing was significantly associated with HCC that showed there was an additive effect between BQ use and chronic infection with either hepatitis $B$ virus (HBV) or hepatitis $C$ virus (HCV) as risk factors of the cancer [22-25]. A communitybased cohort study indicated that BQ chewing habits were associated with the increased risk of HCC, and BQ chewers with hepatitis surface antigen- (HBsAg-) positive had the highest risk of $\mathrm{HCC}(\mathrm{aOR}=19.5 ; 95 \% \mathrm{CI}=8.7-43.4)$ compared with HBsAg-positive subjects without BQ chewing habits and HBsAg-negative BQ chewers [41]. Among HBsAgseronegative subjects, the adjusted relative risk (aRR) of HCC was significantly higher for BQ chewers compared with nonchewers $(\mathrm{aRR}=3.4 ; 95 \% \mathrm{CI}=1.2-9.9)$. In a case-control study, the habit of $\mathrm{BQ}$ use as a risk factor related to the development of HCC has been reported ( $\mathrm{aOR}=3.49 ; 95 \%$ $\mathrm{CI}=1.74-6.96)$ [22]. Moreover, a higher risk of HCC was related to a longer period of $\mathrm{BQ}$ use and a larger quantity of BQ chewed [22, 23]; BQ chewing habit was associated with the occurrence of liver cirrhosis $(\mathrm{aOR}=3.56$; 95\% CI =1.41-8.96) [25]. A recent study demonstrated that habitual $\mathrm{BQ}$ chewers, with or without chronic infection of $\mathrm{HBV} / \mathrm{HCV}$, were associated with a higher risk for the occurrence of HCC $(\mathrm{aOR}=3.73$; 95\% CI $=1.63-8.53)[24]$.

Studies on the health effects of BQ chewing have expanded to include hypertension [29], obesity [43], metabolic syndrome [26, 27], hyperglycemia [26], and hypertriacylglycerolemia [26], where the daily rate of BQ chewing was positively and independently related to these conditions among adults [27]. A population-based study on men further demonstrated an independently predictive doseresponse relationship of $\mathrm{BQ}$ chewing on the development of metabolic syndrome [26]. Indeed, BQ chewing habit was significantly associated with type $2 \mathrm{DM}(\mathrm{aOR}=1.29$; 95\% CI $=1.04-1.60)$ in men [28]. Our previous findings showed the prevalence of BQ chewing to be $46.1 \%$, with this practice being closely related to obesity $(\mathrm{OR}=1.61 ; 95 \% \mathrm{CI}$ : $1.40-1.85)$. Another study found that daily chewing of BQ was independently related to heart disease in women, with a risk associated with BQ mean chewing rate of 10 times per day ( $\mathrm{aOR}=1.37 ; 95 \% \mathrm{CI}=1.1-1.6 ; p=0.003)$ [32]. Additionally, in a Bangladesh cohort study, BQ chewers without tobacco usage had a significant relationship to systolic hypertension $(\mathrm{aOR}=1.55 ; 95 \% \mathrm{CI} 1.01-2.37)$ and hypertension $(\mathrm{OR}=1.48$; 95\% CI 1.04-2.10) after controlling for potential founding variables [29]. Also, data showed that past BQ users were significantly more likely to die from cancer (adjusted hazard ratios $[\mathrm{aHR}]=1.55 ; 95 \% \mathrm{CI}: 1.09-2.22)$ and all causes (aHR: 1.26; 95\% CI: 1.09-1.44) after adjusting for confounding factors, implicating BQ chewing as significantly associated with mortality from cancers and all causes [34]. 


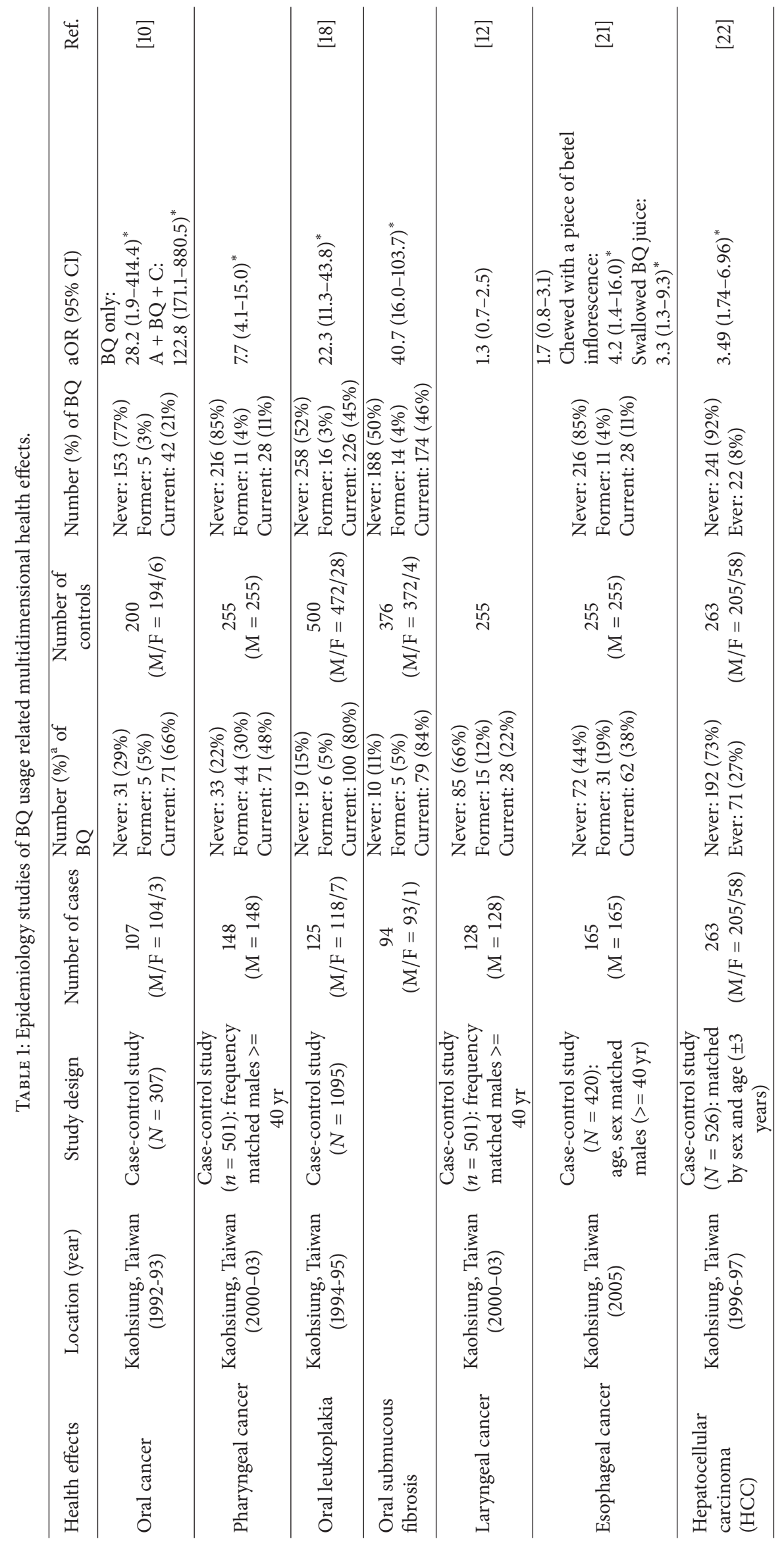




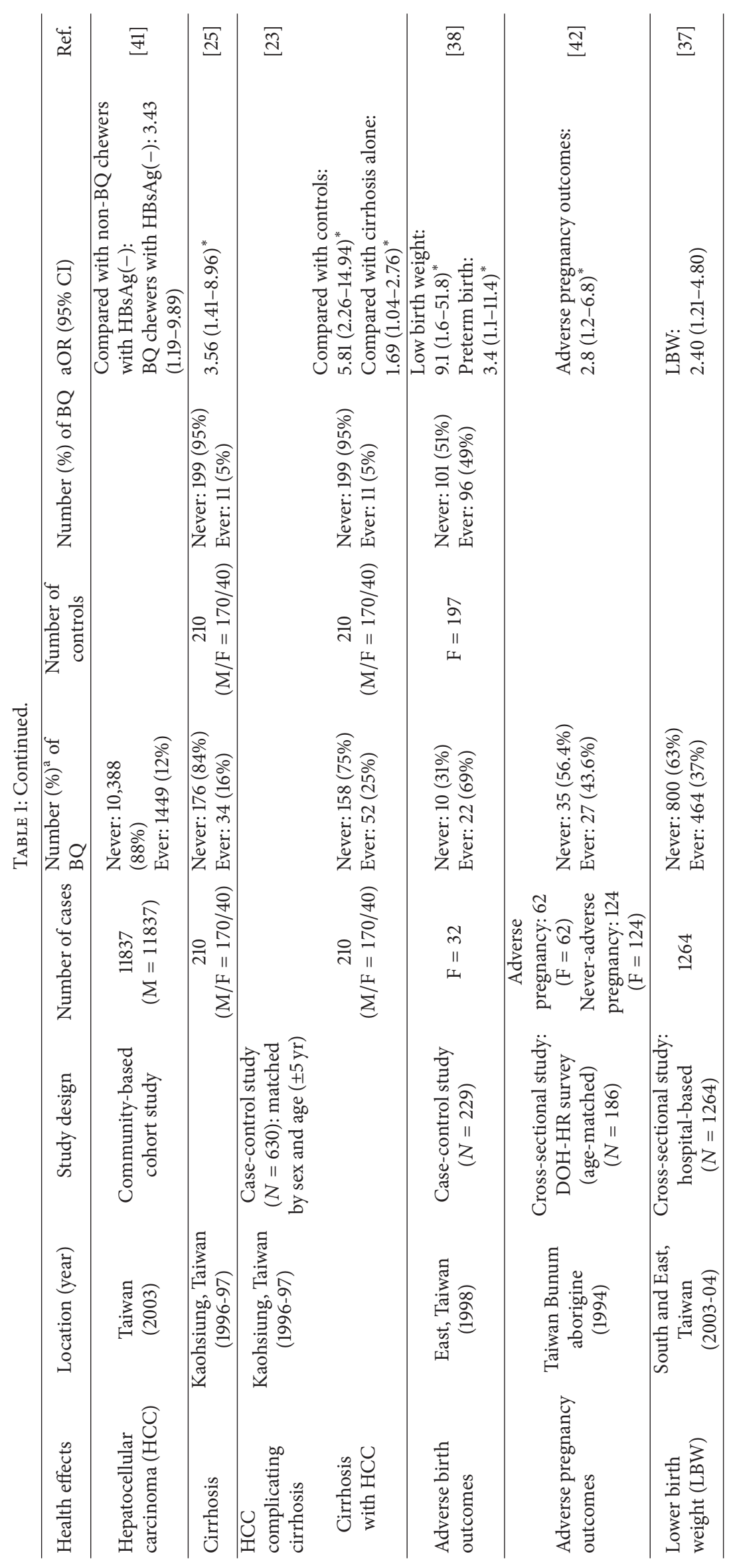




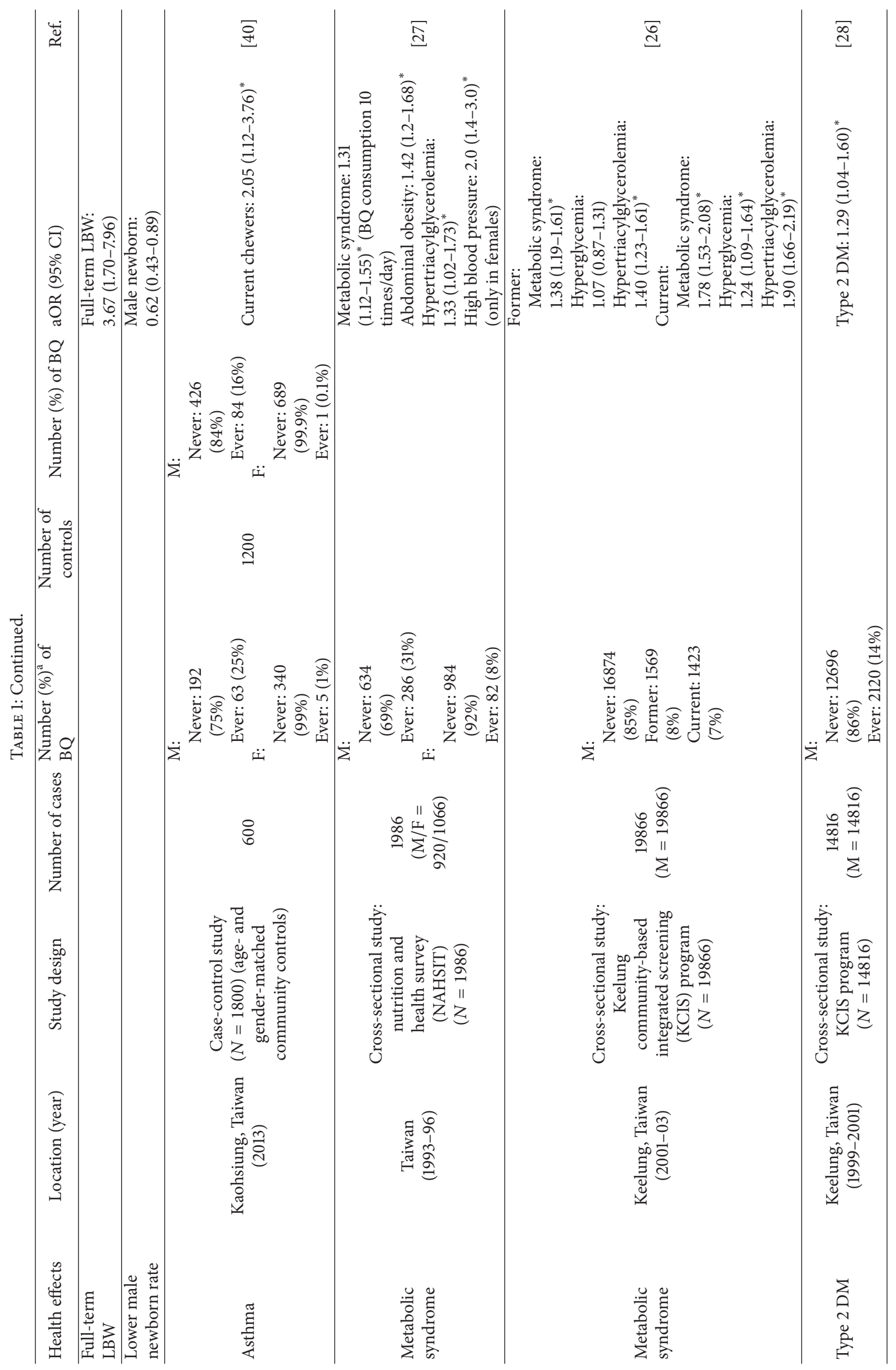




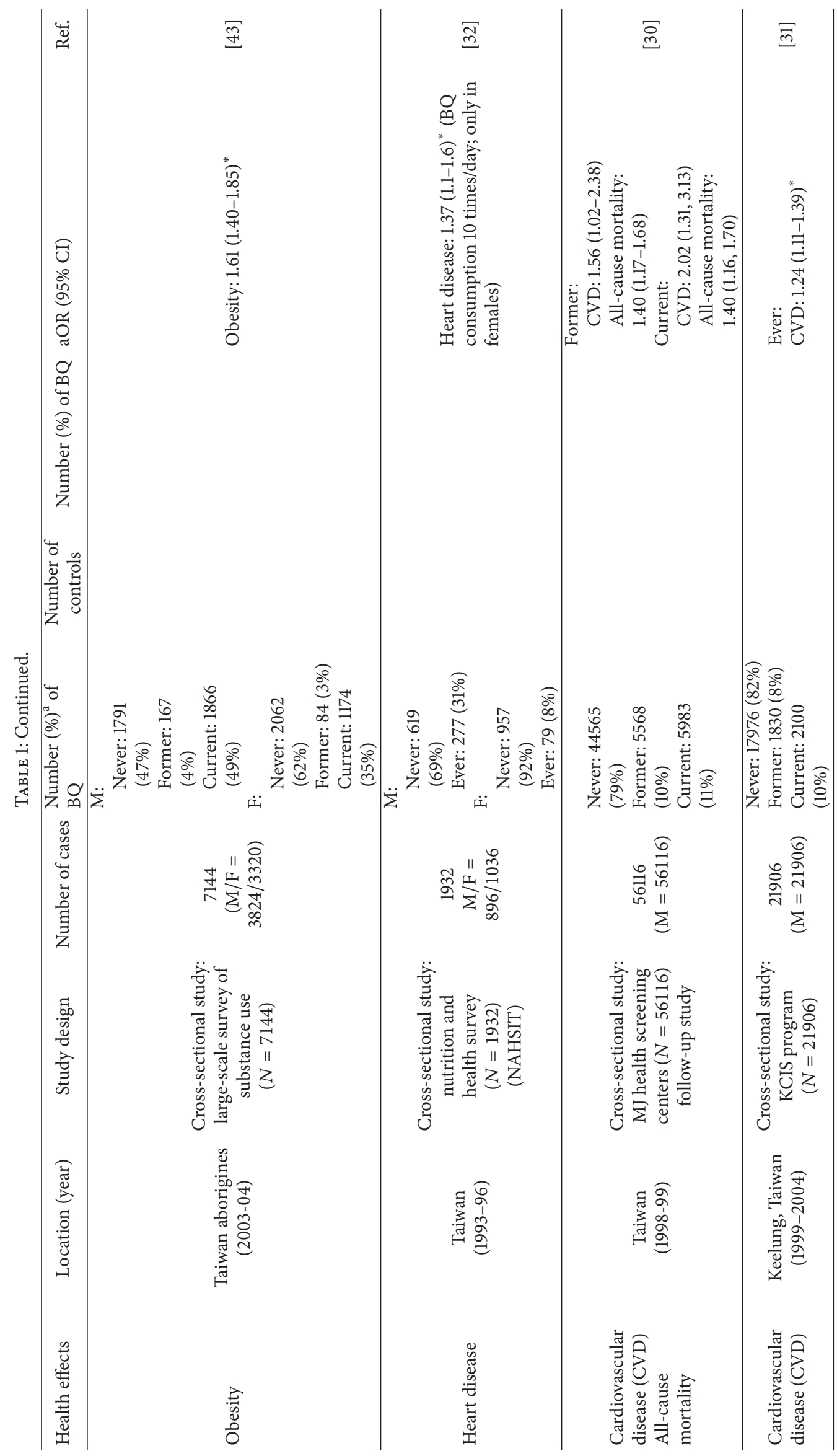




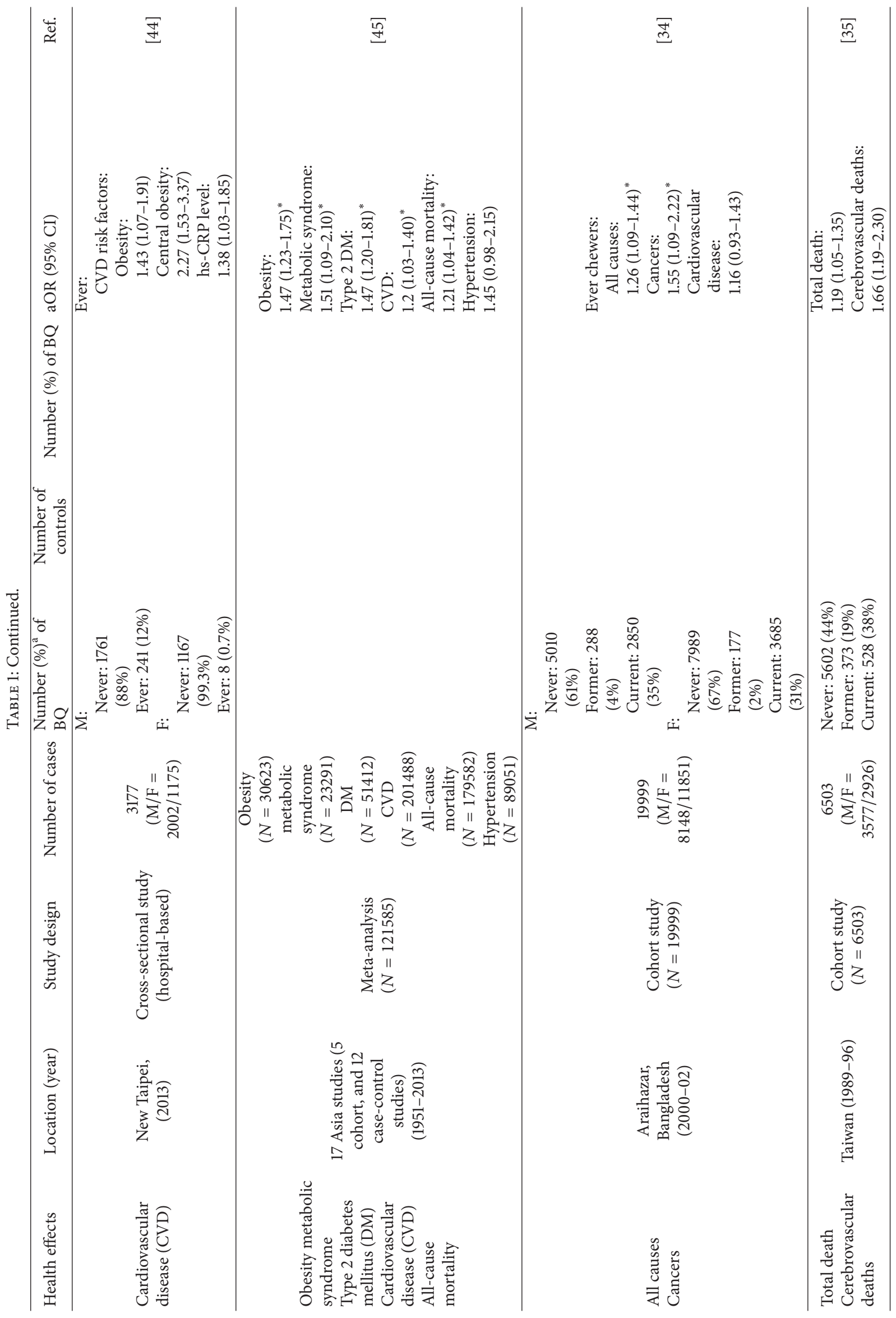




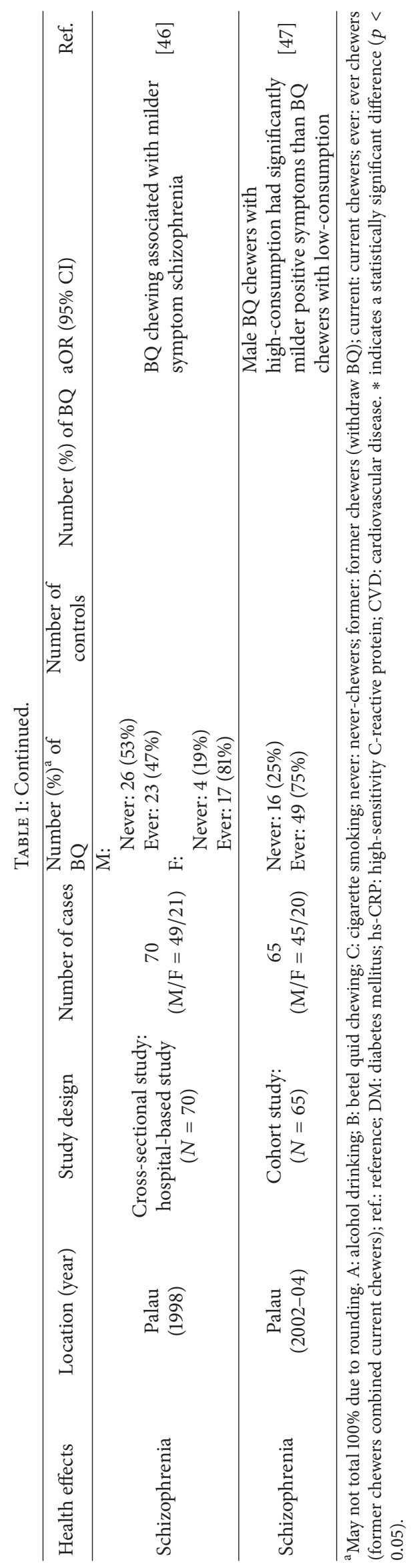


Particularly, BQ use behaviors might be associated with schizophrenia in Palau [46, 47] and Sri Lanka [78]. In Palau, BQ chewers were associated with mild schizophrenia and have a benefit on patients with respect to a decrease of both positive and negative symptoms [46, 47]. However, these associations were not statistically significant in symptoms between BQ users and nonusers in Nepal [79]. The habit of BQ chewing has also been studied for adverse pregnancy outcomes. In a study of 62 women who had adverse effect on pregnancy outcome and 124 age-matched women (control group), the prevalence of substance use in aboriginal women was $43.6 \%$ for alcohol, $43.6 \%$ for BQ chewing, and $14.5 \%$ for cigarette smoking, whereas it was alcohol, 38.7\%; BQ chewing, 28.2\%; and cigarette smoking, $8.1 \%$ in the matched comparison group [42]. The risk of adverse pregnancy effects was 2.8-fold higher among maternal BQ use as compared with non-BQ users $(\mathrm{aOR}=2.8 ; 95 \% \mathrm{CI}=1.2-6.8)$ [42]. A further study of 229 aboriginal women showed that an estimated risk of harmful birth outcome was statistically significantly higher among women with the habits of BQ use as compared with nonusers $(\mathrm{aOR}=5 ; 95 \% \mathrm{CI}=1.1-23.0)$ [38]. In another study in Taiwan aborigines that included 1264 postpartum aboriginal women who used BQ during gestation were significantly related to both lower birth weight (LBW) $(-89.54 \mathrm{~g})$ and lower birth length $(-0.43 \mathrm{~cm})$ [37]. Thus, women who had chewed BQ throughout pregnancy conveyed a $2.40-(95 \% \mathrm{CI}=1.21-4.80)$ and 3.67 -fold $(95 \%$ $\mathrm{CI}=1.70-7.96)$ independent risk effects for LBW and fullterm LBW on gestation, respectively, and chewers were more likely to have female newborn than nonchewers [37]. Indeed, a significantly lower rate of male newborns at birth $(\mathrm{aOR}=$ $0.62 ; 95 \% \mathrm{CI}=0.43-0.89)$ was also observed to be associated with BQ use alone during gestation [37]. A previous animal study has indicated the influence of areca nut extract (ANE) on male reproduction. Male rats were given ANE by gavage to characterize reproductive toxicity resulting from ANE exposure [80].

\section{Prevalence of BQ Chewing among Adults and Selected Hyperendemic Countries for Oral and Pharyngeal Cancers (Table 2)}

Using data from the GLOBOCAN 2012 statistical database of estimated cancer incidence, mortality, and prevalence worldwide 7 [76], we summarized the international comparisons between the prevalence of BQ chewing and oral/pharyngeal cancer incidences (Table 2). We can identify a positive trend between oral and pharyngeal cancer incidence and BQ chewing rates in different countries. Populations with high chewing rates often have a higher incidence rate of oral and pharyngeal cancers than other countries. In BQ endemic areas, a close association is observed between a higher prevalence of BQ chewing and the age standardized rate adjusted by the world population (ASRW) for the incidence/mortality rate of oral and pharynx cancers.

In some countries (e.g., Malaysia [9] and Thailand [49]), the intermediate proportion of $\mathrm{BQ}$ use may result in an intermediate incidence of oral and pharyngeal cancers. There are no BQ chewing habits in some countries, such as Singapore, Japan, and Korean. Occurrences of oral and pharyngeal cancers might also be due to cigarette or alcohol consumption [9]. Thus, in most countries, BQ chewing has a modifying effect or causes an interaction with the practices of cigarette or alcohol to induce oral and pharyngeal cancers. However, there is a close relationship between oral/pharyngeal cancers and the higher prevalence of BQ use in endemic BQ chewing areas.

3.1. Taiwan. In Taiwan, the incidence (2012 ASRW) adjusted by the 2000 world-standard population for oral and pharyngeal cancers was 41.7 per 100,000 among men and 3.5 per 100,000 among women [77]. According to the latest 2014 Taiwan Cancer Registry data, the incidence and mortality rates (the rates were adjusted by world population in 2000) of men with cancers of oral and pharynx are as high as 42.85 and 15.41 per 100,000 male population, respectively [81]. According to the IARC, Taiwan reported a 44-fold increase in AN production between 1961 and 2001 [9], which could lead to a rapid growth in oral and pharyngeal cancer incidences in the future. Indeed, from 2007 to 2014, there were more than 5,000 new cases of men with the cancers of oral and pharynx each year and this has continued to increase to 7,600 cases in Taiwan [82]. In the past 10 years (2004-2014), the incidence and mortality rates of oral and pharyngeal cancers for men were stable elevation and ranked fourth in cancer occurrence and deaths [82].

In a 2007 published international comparison, the fourth highest incidence of cancers of oral and pharynx among males was ranked in Taiwan, followed only by Papua New Guinea, the Solomon Islands, and Sri Lanka [4]. Oral and pharyngeal cancers are prevalent in Taiwan, particularly in male BQ chewers. Correspondingly, previous studies indicated that the prevalence of BQ chewers is $14.5 \%-16.5 \%$ in men $[48,67,69]$. There are two million habitual BQ chewers in Taiwan alone (approximately $10 \%$ of this island's people) [67]. BQ is usually practiced by men (men: $16.5 \%$; women: $2.9 \%$ ) [67], lower education level, blue-collar job, subjects with smoking habits, alcohol drinkers, and Taiwan aborigines. A national survey indicated that men had a higher rate of BQ chewing than women (men: $20.9 \%$; women: $1.2 \%$ ) [70]. In this survey, the highest rate of BQ chewing was among Taiwan aborigines: $54.3 \%$ of men and $33.8 \%$ of women [70]. However, another aboriginal study revealed that current chewing habits were more common among women $(78.7 \%)$ than men $(60.6 \%)$ [83]. In national health study, the lifetime chewing rates (combined analysis of current-chewers and exchewers) were also found to be relative higher in men (18.9\%) as compared to women (1.7\%) [68].

Recently, an intercountry survey of Asian betel-quid consortium also revealed that the proportion of BQ chewing among Taiwanese men (15.6\%) was significantly higher than that among Taiwanese women (3.0\%) [48]. Currently, there are no legal age restrictions that must be strictly observed for BQ use. In adolescents, the proportion of BQ was practiced by $31.0 \%$ of the vocational school students $(36.1 \%$ for boys; $8.3 \%$ for girls) compared with $14.0 \%$ of the junior high school students (24.4\% for boys; $5.0 \%$ for girls) [84]. As shown in 


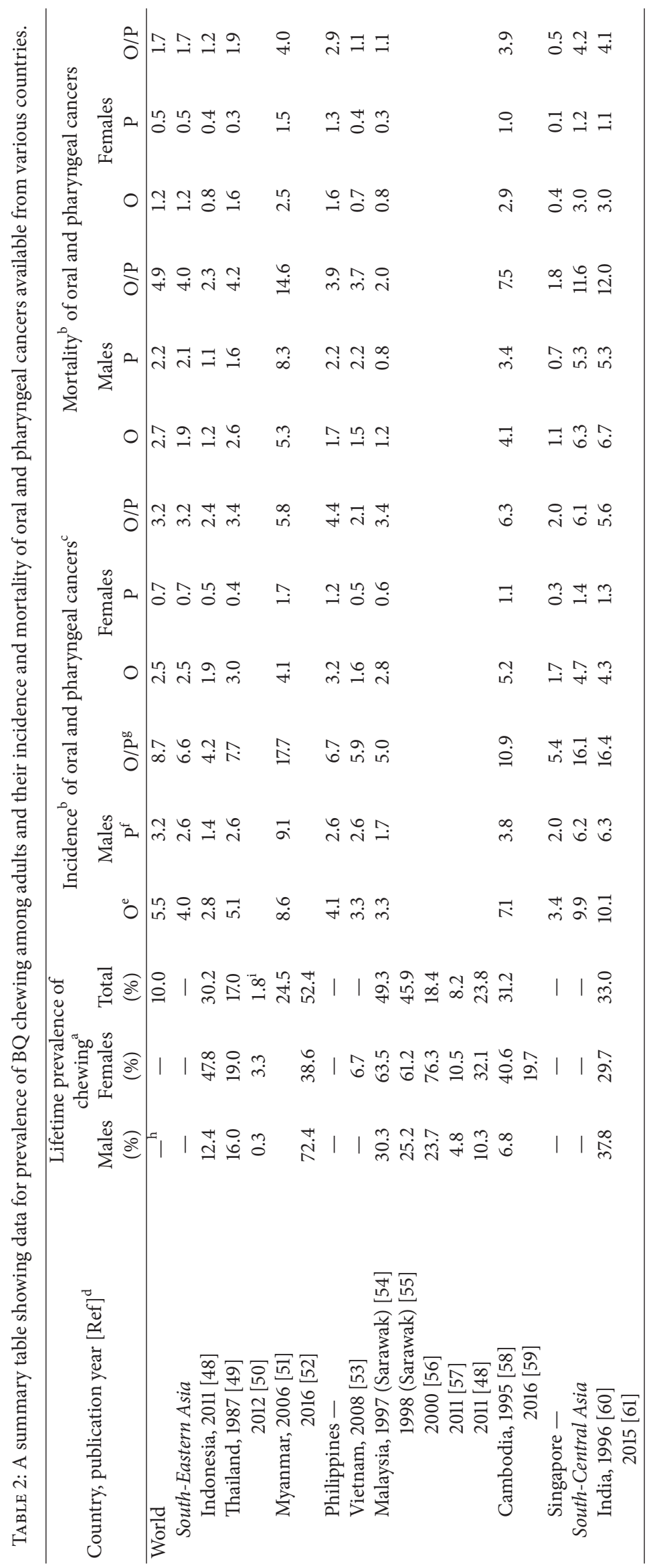




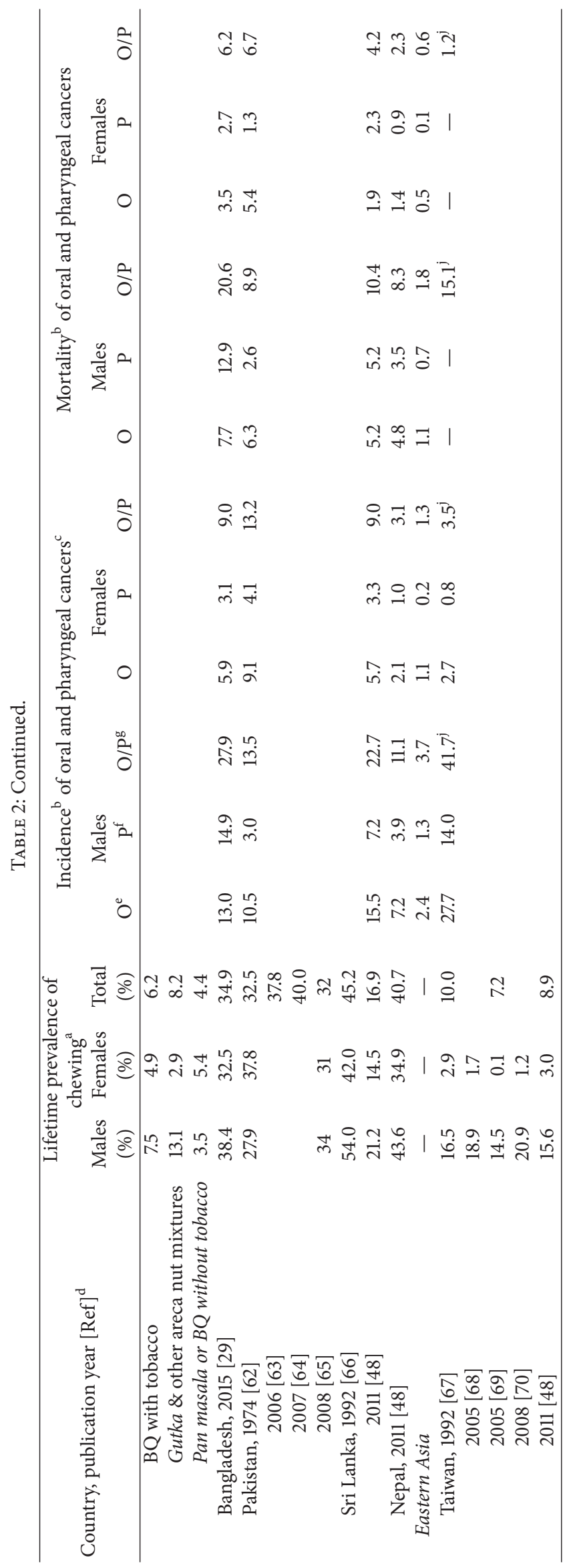




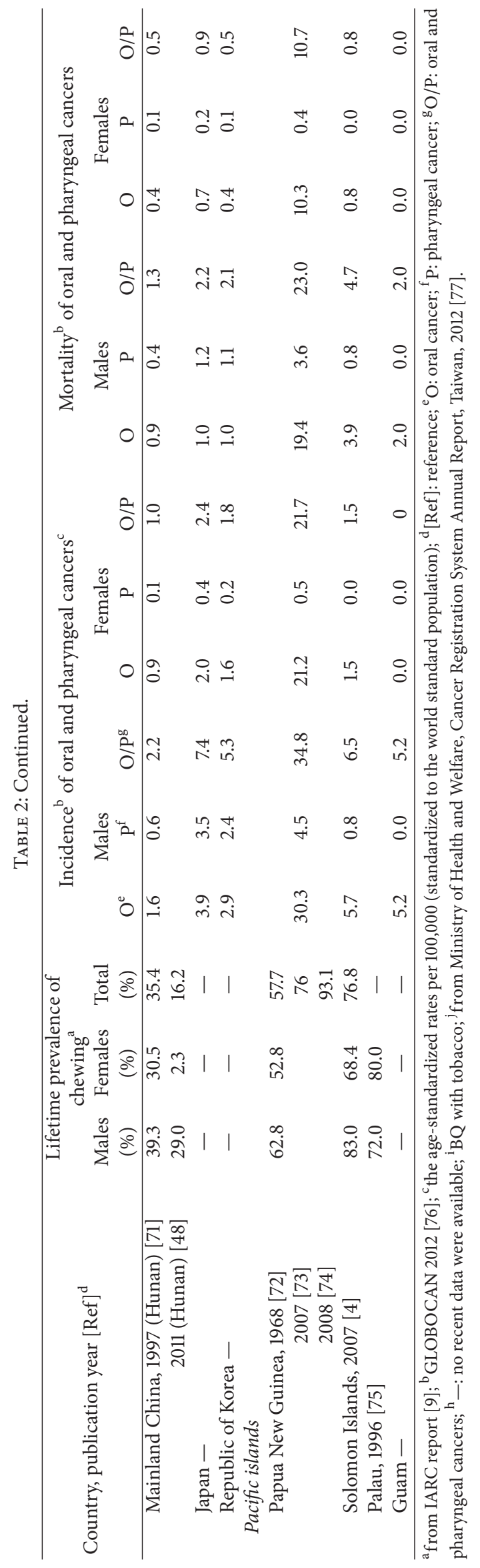




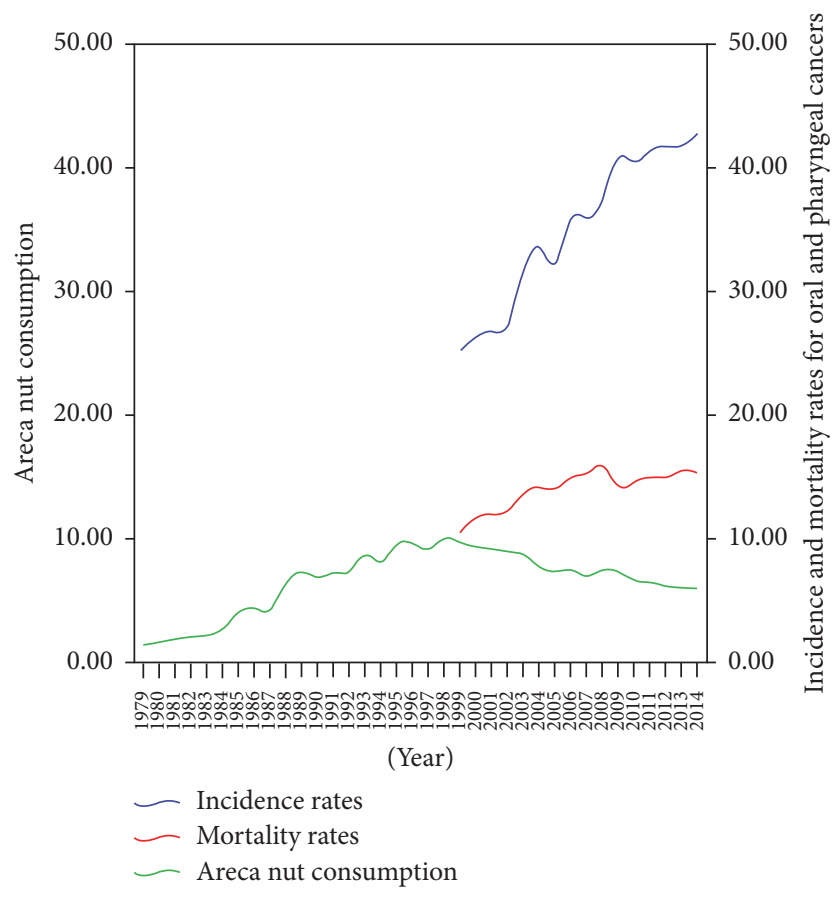

FIGURE 1: The long-term trend of incidence and mortality (ASRW) due to oral and pharyngeal cancers among males (per 100,000 population) and areca nut consumption $(\mathrm{kg})$ of per person (population of 15 years) per year in Taiwan.

Figure 1, the green line is the estimated per person per year areca nut (AN) consumption $(\mathrm{kg})$; blue lines and red lines are age-standardized rates of incidence and mortality for oral and pharyngeal cancers (per 100,000 men population) showing the long-term trend (1999-2014). It is noteworthy that the incidence and mortality rates of oral and pharyngeal cancers showed a steady upward trend from 1999 to 2014. In Taiwan, if we cannot propose an effective preventive and controlling strategy for BQ-related oral and pharyngeal cancers; this situation will continue to deteriorate, and oral and pharyngeal cancer incidences will soon be the highest in the world. Therefore, control and prevention strategies of the occurrence of oral and pharyngeal cancers are an indispensable issue.

Almost $80 \%$ of oral and pharyngeal patients have BQ chewing habits and epidemiological studies suggest that BQ use significantly elevates the risks of oral and pharyngeal cancers $[10,11,19]$. Compared with no-chewers, BQ chewers will develop oral and pharyngeal cancers 10 years earlier, with lower 5-year survival rates and their oral mucosal lesions are 8.21 times larger than nonchewers [85]. Therefore, BQ chewing habits are closely related to the occurrence and prognosis of oral and pharyngeal cancers. In regard to BQrelated oral and pharyngeal cancer survival, we reported that Taiwanese men have a high prevalence of BQ use and this habit is related to poor survival rates observed [86]. The 5-year survival rates of oral and pharyngeal cancers are significantly lower for the community of Hokkien people (Han Chinese) (53.9\%) and the Taiwanese aborigines (58.1\%) than Hakka community (60.5\%). Genetic predispositions and lifestyle habits (e.g., BQ chewing, cigarette smoking, and alcohol drinking) were considered as crucial factors in the differences of survival among racial groups with respect to oral and pharyngeal cancers [87].

3.2. Papua New Guinea. In the population of Papua New Guinea, the incidence (2012 ASRW) of oral and pharyngeal cancers among men was 34.8 per 100,000 and 21.7 per 100,000 among women. Also, the rate of BQ use was higher $(57.7 \%)$ in Papua New Guinea, $62.8 \%$ for men and 52.8\% for women [72]. However, the Papua New Guinea statistical data are from nearly 49 years ago and conceivably this is necessary to be reinvestigated. Two relatively new studies also reported very high rates of lifetime chewing (76\% and $93.1 \%$, resp.) $[73,74]$.

3.3. Bangladesh. In Bangladesh, the incidence (2012 ASRW) of oral and pharyngeal cancers in men was 27.9 per 100,000 and 9.0 per 100,000 in women. A prospective populationbased study (19,934 Bangladeshi adults) found that the proportion of current BQ chewers was $33.2 \%$ in this cohort (35.5\% of men and $31.6 \%$ of women, resp.); the lifetime chewers were $34.9 \%$ (38.4\% of men and $32.5 \%$ of women, resp.) [29].

3.4. Sri Lanka. The estimated incidence (2012 ASRW) of oral and pharyngeal cancers was still higher in Sri Lanka and the rate in men was 22.7 per 100,000 and 9.0 per 100,000 in women. In a large-scale survey, the proportion of BQ chewers was $45.2 \%, 54.0 \%$ for men and $42.0 \%$ for women, respectively [66]. More recently, an international survey by Asian BQ Consortium study indicated that the prevalence of BQ chewers was only $16.9 \%$ (21.2\% for men and $14.5 \%$ for women) [48].

3.5. Myanmar. The oral and pharyngeal cancer incidences (2012 ASRW) were calculated to be 17.7 per 100,000 among men and 5.8 per 100,000 among women in the Myanmar population. An early report indicated that $24.5 \%$ were BQ chewers (combine $16.2 \%$ regular chewers with $8.3 \%$ occasional chewers) [51]. Recently, a higher chewing rate was found in Dagon Myothit (East) Township, Myanmar; there, $52.4 \%$ of subjects indulged in the habit $(72.4 \%$ for men and $38.6 \%$ for women) [52].

3.6. India. In India, the 2012 ASRW for oral and pharyngeal cancer incidences was also noted to be high (16.4 per 100,000 for men and 5.6 per 100,000 for women). India has the largest population of BQ consumption worldwide. In Mumbai (Bombay), India, a previous large-scale survey reported that $33.0 \%$ chewers used $\mathrm{BQ}$ in all forms, $37.8 \%$ among men and $29.7 \%$ among women, respectively [60]. However, only $0.4 \%$ of men and $0.5 \%$ of women used $\mathrm{AN}$ without tobacco [60]. A survey on AN habits and tobacco was conducted in the Global Adult Tobacco Survey (GATS) of India [61]. This survey reported that $6.2 \%$ subjects (men, $7.5 \%$; women, $4.9 \%$ ) chewed BQ with tobacco; $13.1 \%$ of the men and $2.9 \%$ of the women added tobacco and lime to the Gutka and other areca nut mixtures [61]. In addition, the prevalence 
of Pan masala or BQ without tobacco was 3.5\% for men and $5.4 \%$ for women [61].

3.7. Pakistan. In Pakistan, the incidence (2012 ASRW) of oral and pharyngeal cancers was 13.5 per 100,000 men and 13.2 per 100,000 women. There was a high proportion of BQ use and an elevated incidence rate of cancers of oral and pharynx in Pakistan. In 1974, there were $32.5 \%$ subjects currently in the habit of chewing BQ (27.9\% for men and 37.8\% for women) [62]. A few previous studies indicated that the prevalence of AN use among adults was $32 \%, 37.8 \%$, and $40 \%$, respectively [63-65].

3.8. Nepal. The 2012 ASRW for oral and pharyngeal cancer incidence was also higher (11.1 per 100,000 for men and 3.1 per 100,000 for women) in Nepal. Recently, the national population-based survey reported that the prevalence of BQ chewers was $40.7 \%$ (43.6\% for men and $34.9 \%$ for women) [48].

3.9. Cambodia. In Cambodia, the 2012 ASRW for oral and pharyngeal cancer incidence was 10.9/100,000 per annum for men and 6.3/100,000 per annum for women. Moreover, an earlier report indicated that $31.2 \%$ subjects were habitual BQ chewers (6.8\% for men and $40.6 \%$ for women) [58]. Recently, in a population-based study conducted among Cambodia adults, $19.7 \%$ of women indulged in the BQ habits [59]. In addition, the highest risk of OPMD was associated with BQ chewing habits [59].

3.10. Thailand. In Thailand, the incidence (2012 ASRW) of oral and pharyngeal cancers was 7.7/100,000 per annum for men and 3.4/100,000 per annum for women. In northern Thailand, a previous study reported only $2.6 \%$ of subjects were occasional BQ users, and $6.8 \%$ chewed it daily. Daily BQ chewers were most prevalent in the group aged 50 years and above (22.7\% of women and $18.4 \%$ of men) [88]. The BQ chewing habit seems to be on the decline from educational campaigns since the early 1955, and this habit has been indicated more popular in the older population [89]. The Global Adult Tobacco Survey (2011) illustrated that the proportion of current use of BQ with tobacco was $0.3 \%$ among men and 3.3\% among women in Thailand [50].

3.11. Solomon Islands. The GLOBOCAN 2012 statistical database showed that the ASRW of oral and pharyngeal cancers dramatically decreased at 6.5/100,000 per annum for men and 1.5/100,000 per annum for women, but the 5-year prevalence rate per 100,000 was still maintained at 26.0 for men and 4.2 for women [90]. It was noteworthy that the incidence (2002 ASRW) of oral and pharyngeal cancers in the Solomon Islands was very high at 37.0 per 100,000 men and 22.5 per 100,000 women from GLOBOCAN 2002 statistical database [91]. In our previous Solomon Islands study, BQ chewing was very popular in both men $(83 \%)$ and women (68\%) [4].

3.12. Malaysia. In Malaysia, the incidence for oral and pharyngeal cancers was 5.0/100,000 per annum for men and
$3.4 / 100,000$ per annum for women in 2012. The BQ chewing rate was more prevalent among women [56]. Previous studies were conducted in Sarawak, Malaysia, and showed that chewing rates among indigenous women (61.2-63.5\%) were significantly higher than men (25.2-30.3\%) [54, 55]. Indeed, in 2011, an intercountry Asia BQ study indicated that the habit pf BQ chewing was more common in women $(32.1 \%)$ than in men $(10.3 \%)$ [48].

3.13. Indonesia. The 2012 ASRW for oral and pharyngeal cancers per 100,000 population was 4.2 among men and 2.4 among women in Indonesia. An intercountry Asian BQ survey demonstrated that the habit of BQ chewing was more popular among women (47.8) than among men (12.4\%) [48].

3.14. Mainland China. In China, the incidence (2012 ASRW) of cancers of oral and pharynx was 2.2 per 100,000 men and 1.0 per 100,000 women. The BQ chewing habit is common only in Hunan, Hainan, and Yunnan. A previous study was conducted to evaluate the relationships between BQ usage and OSF in Xiangtan City, Hunan Province [71]. A total of 11,046 individuals were examined, and the proportion of lifetime chewing was $39.4 \%$ for men and $30.5 \%$ for women, respectively [71]. However, in a recent epidemiological study, the lifetime chewing rates among men $(29.0 \%)$ were statistically prominently higher than that among women $(2.3 \%)$ in Hunan. In the 1980s and 1990s, a review article indicated that the proportion of BQ chewers in Xiangtan and Changsha of Hunan was between $64.5 \%$ and $82.7 \%$ [92].

\section{What Are the Main Chemically Carcinogenic Substances of BQ That Induce Oral and Pharyngeal Cancers?}

The composition of BQ ingredients varies greatly depending on the way they are used in different areas. However, AN is the basic constituent of a variety of widely practiced BQ, and its main constituents are BQ alkaloids and polyphenols that might be associated with the cancers of oral and pharynx.

4.1. Overview of the Carcinogenesis of Arecoline and Arecaidine. Most evidence demonstrates that areca alkaloids (arecoline and arecaidine) are the major causes of toxicity from AN. The IARC points out that arecoline has limited evidence for carcinogenicity in animal experiments and arecaidine has inadequate evidence in animal experiments [9]. In mammalian cells, arecoline and arecaidine can cause bacterial mutagenicity, and in vitro and in vivo tests can result in the exchange of sister chromatid, aberrations of chromosome, and the formation of micronuclei [9]. In addition to the ANE, arecoline also causes dysregulation of oral epithelial cells, leading to cell cycle arrest [93]. Arecoline and ANE can repress the growth of different oral cells (such as oral mucosa fibroblasts, gingival fibroblasts, and keratinocytes) and induce genotoxicity [94-98]. Studies of its chemical components have indicated that AN contains 11-26\% tannins (a category of stimulant) and 0.15-0.67\% alkaloids (a major component of which is arecoline) [5, 99]. Among these 

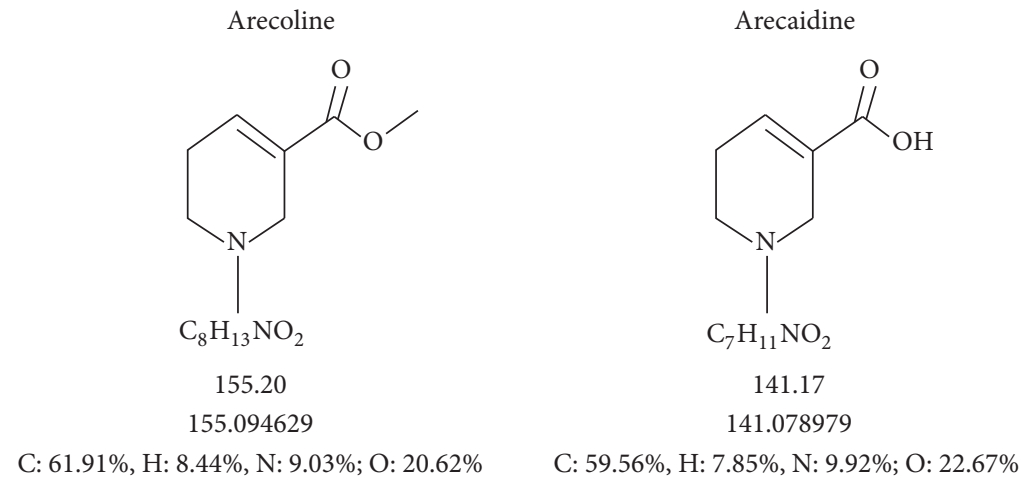

Figure 2: Chemical structure of major areca alkaloids [15].

components, arecoline has a chemical structure similar to that of nicotine [9].

\subsection{BQ Toxicology Research}

4.2.1. Ultramicro-Mass Analysis of the Internal Dose and Effective Dose of Toxicants. Although little is known about the disposition and metabolism of areca alkaloids (arecoline and arecaidine) and 8-hydroxy-2-deoxyguanosine (8-OH-dG) in humans, we conducted an accurate and sensitive technique to explore the exposure of toxic substances from BQ consumption [15]. Using a method of liquid chromatography-tandem mass spectrometry (LC-MS/MS), given the cytotoxic effects of arecoline and arecaidine, its direct quantification from a chewing habit was determined by [15]. The average daily amount (quids/day) shows a significant association with both arecoline $(r=0.52)$ and arecaidine levels $(r=0.51)$. This means the blood measurements of these two alkaloids are good indicators for recent BQ use. We believe that arecoline and arecaidine of blood plasma are appropriately biological indicators for short-term or immediate exposure of BQ. In blood plasma, arecaidine is a better clinical marker of BQ exposure than arecoline. In contrast to urinary $8-\mathrm{OH}-\mathrm{dG}$, which is known to have risks on human, it is not significantly correlated to BQ exposure. We have been able to determine the levels of toxicants with ultramicro analysis in vivo. Once ingested, BQ is metabolized and its metabolites, such as arecoline, arecaidine, and others, may exist only at nanogram concentrations $(\mathrm{ng} / \mathrm{mL}$ ). After chewing inverted AN (pinangwang BQ), we also reported that high concentrations of arecoline and arecaidine may cause ventricular fibrillation [100].

BQ alkaloids let BQ chewers feel a refreshing, exciting, and warm feeling. Arecoline is the main alkaloid ingredient in BQ followed by arecaidine. Arecoline is hydrolyzed into arecaidine in the mouth of chewers. Its chemical structure is shown in Figure 2 [15]. Following human exposure, we determined the main BQ alkaloids, arecoline and arecaidine, by quantitative and qualitative analysis through LC-MS/MS. We found that arecoline and arecaidine $(7.0 \pm 10.7 \mathrm{ng} / \mathrm{mL}$ and $142.8 \pm 249.3 \mathrm{ng} / \mathrm{mL}$, resp.) levels in the BQ chewers' blood were significantly higher than nonchewers [15]. In addition, we found that chewed BQ quids per day and the amount of BQ chewing before drawing blood from the patient were significantly positively related to the concentration of arecoline or arecaidine in human blood [15].

4.3. AN Polyphenols Produce Reactive Oxygen Species. The major substances contained in the areca nut are polyphenolic compounds (tannins and flavonols), alkaloids, carbohydrates, fats, proteins, crude fiber, and minerals. A large proportion of AN dry weight is polyphenols that result in the astringent taste of AN [9]. Hence, in order to eliminate this astringency, the traders often add lime to the $\mathrm{BQ}$. The polyphenols and tannins in AN play dual roles through both carcinogenetic and anticarcinogenic effects [98]. In BQinduced tumors, AN polyphenols and tannin fractions are considered potential carcinogens [98]. However, results of many short-term experiments assays have indicated that the tannins and polyphenols of AN are not mutagenic, and conversely, they are antimutagenic. For example, some reports indicate that polyphenols can conjugate with carcinogens to bind ROS and nitrite. Conversely, a series of studies have demonstrated that the interaction between $\mathrm{AN}$ polyphenols and lime is the major determinant in the generation of reactive oxygen species (ROS) such as hydroxyl radical $\left(\mathrm{HO}^{\circ}\right)$ during BQ chewing [101-105].

Although the lime itself is not mutagenic, it will make the oral environment alkaline. The polyphenolic ingredients mixed with lime in $\mathrm{BQ}$ produce $\mathrm{ROS}$, such as $\mathrm{HO}^{\circ}$ in alkaline conditions $(\mathrm{pH} \geq 9.5)$ [106]. The lime added to the BQ is indispensable to the formation of ROS and forms a hydroxyl group via the transition metal-catalyzed Haber-Weiss or via the Fenton reaction to further form the $8-\mathrm{OH}-\mathrm{dG}$ that can destroy DNA. In vitro studies have indicated that the $\mathrm{HO}^{\circ}$ generation is enhanced by the catalysis of metal ions such as $\mathrm{Cu}^{2+}$ and $\mathrm{Fe}^{2+}$, and possible oxidative DNA damage is due to the generation of $8-\mathrm{OH}-\mathrm{dG}[102,104,107]$. This genetic damage has been associated with oral cancer [101$104,107,108]$. In the saliva of BQ chewers, ROS produced from AN polyphenols is crucial to initiate and promote the development of oral and pharyngeal cancers [98]. Our previous study found that chewing BQ with inflorescence of Piper betle Linn. (IPB) produced significantly higher amounts of $\mathrm{HO}^{\circ}$ than chewing BQ with Piper betle leaf (PBL) 
Arecoline-specific N-nitrosamines

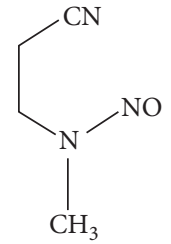

3-Methyl-

nitrosamino-

propio-nitrile

(MNPN)<smiles>CN(CCC=O)N=O</smiles>

3-Methyl-

nitrosamino-

propion-

aldehyde

(MNPA)<smiles>CC(=O)C1=CCCN(N=O)C1</smiles>

N-Nitroso-

guvacoline

(NGL)<smiles></smiles>

N-Nitrosoguvacine (NGC)

FIGURE 3: Arecoline can be formed as AN-specific nitrosamine substances (areca-specific N-nitrosamines) by nitrosation reaction in the human body [16].<smiles>CN1CCCC1c1cccnc1</smiles>

Nicotine (major tobacco alkaloid)<smiles>CC(=O)C1=CCCN(C)C1</smiles>

Arecoline

(major areca nut alkaloid)

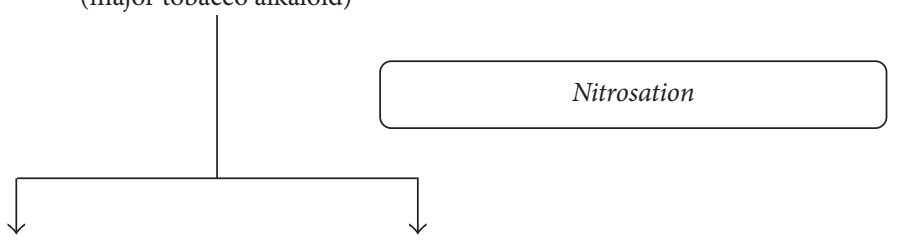<smiles>O=[N+]1CC2C(c3cccnc3)CCC21</smiles>

NNN<smiles>CN(CCCC(=O)c1cccnc1)N=O</smiles>

NNK<smiles>CN(CCC#N)N=O</smiles>

MNPN

FIGURE 4: Major BQ alkaloids (arecoline) and major tobacco alkaloids (nicotine) can form nitrosamine substances by nitrosation reaction [17].

and may induce larger oxidative stress damage to the cells of oral mucosa [109]. If this trend is repeated, long-term accumulation in the body will cause oxidative damage to the cells [110]. Epidemiological studies also support that ROS might be responsible for the possible mechanism of the oral malignant tumor process [111], and we further assume that active oxygen species may play a crucial role in BQ-related oral and pharyngeal cancers [106].

4.4. Overview of Carcinogenicity of Nitroso Compounds in $A N$. Some researchers reported that arecoline can produce nitrosamine through a nitrosation reaction in the digestive tract of the human body. Thus, BQ chewers swallowing $B Q$ juice will increase their exposure to nitrosamine during the BQ chewing process [112]. The BQ chewing process will produce areca-specific nitrosamine substances that are known as $\mathrm{N}$-nitrosoguvacine (NGC), N-nitrosoguvacoline (NGL), 3-methylnitrosaminopropionaldehyde (MNPA), and 3-methylnitrosaminopropionitrile (MNPN) (Figure 3) [16]. The most carcinogenic is MNPN, which is different from NNN and NNK during the nitrosamine reaction to chewing tobacco. MNPN can induce abnormal cell proliferation and carcinogenesis (Figure 4) [17].

Studies have shown that MNPN has a concentration of 0.5 to $11.4 \mu \mathrm{g} / \mathrm{L}$ [113] in BQ chewers (excluding tobacco use). In addition, MNPN is carcinogenic in rat experiments. The IARC suggested that MNPN has sufficient evidence for carcinogenicity in experimental animals and is likely to be carcinogenic for humans (Group 2B) [9]. The carcinogenic capacity of MNPN may be due to easy formation of DNA methylation when MNPN is metabolized [98]. 
4.5. Molecular Mechanisms or Pathways Other Than Toxic Responses Involved in the Occurrence and Development of Oral and Pharyngeal Cancers. Numerous molecular mechanisms or pathways other than toxic responses, involving autophagy, hypoxia, COX-2, NF- $\kappa \mathrm{B}$ activity, and stemness are known to be induced by $B Q$ ingredients and are very closely linked with the carcinogenesis of cancers of oral and pharynx. We have summarized these as follows.

Autophagy, a lysosomal degradation pathway, is an important process for cellular physiology and human health [114]. It is a pathogenesis modulator and potential treatment target for various diseases through regulation of pathogen elimination, apoptosis, immune system reaction, and cell development. When autophagy is activated or impaired, the oral cavity can be disturbed, because autophagy affects different functions and processes in the cavity, and the prognosis of the oral disease [115]. Autophagy plays dual function in the progress of oral and pharyngeal cancers [116]. Autophagyinduced tumor suppressor function is regulated by the removal of damaged oxidized organelles, which prevents the release of free radicals of oxygen that induce genomic instability [114]. In some studies, it is indicated that autophagy can boost tumor cells' survival during the development of cancer. Indeed, autophagy renders a protective function to limit the necrosis of tumor and inflammation and to lessen genome damage of tumor cells for metabolic stress or under poor nutrition conditions, particularly in solid and metastasizing tumors [115].

The upregulation of autophagy is likely to be the mechanism of cellular self-defense under stressful environmental conditions, which can protect tumor growth and may regulate tumor cells against therapy-induced apoptosis [115]. Treatment of oral cancer cells with ANE induced autophagy, which was identified through the accumulation of microtubulerelated protein $1 \mathrm{~A} / 1 \mathrm{~B}$ light chain 3 -II (LC3-II) protein, the generation of autophagosomes, and the emergence of GFPLC3 puncta. This action was regulated by the activation of p38, MKP-1, and hypoxia-inducible factor- $1 \alpha$ (HIF1- $\alpha$ ). The autophagy reaction was reduced by downregulation of ANEmodulated HIF1- $\alpha$ expression. The ANE-induced autophagy played a role in enhancing the portion of oral cancer cells undergoing the process of apoptotic death. It is clear that the ANE regulates a signaling cascade that causes the expression of HIF1- $\alpha$ in oral cancer cells. It was beneficial to the survival of cell from ANE-induced apoptosis in the eventual stimulation of autophagy [117]. The mechanisms of autophagy provide new insights into the pathogenesis of oral disorders and highlight their prominent roles in the development of oral carcinogenesis.

Hypoxia plays a critical role in oral cancers, pharyngeal cancers, and OPMD [118]. Cells under conditions of hypoxic stress may present many responses including increased angiogenic capacity, metabolic changes, and modified growth and survival of cells. The hallmarks of cancer consist of six biological events that happen in multiple separate steps in humans, namely, sustaining the proliferation of signaling, the resistance of cell death, evading growth suppressors, enabling replicative immortality, the induction of angiogenesis, and the activation of invasion and metastasis [119]. Risk factors (e.g., alcohol, BQ, and cigarette) use may activate the transcription of hypoxia responsive genes. HIF1- $\alpha$ is the major regulator of cellular responses to hypoxia [118]. The energy metabolism reprogramming and destruction of evading immune are emerging aspects of cancer that are significantly controlled by hypoxia-induced genes that mediate tumor angiogenesis, vascularization, invasion, metastasis, and drug resistance $[118,120]$. In light of the multifactorial nature of tumor angiogenesis, reducing hypoxia is one of the possible approaches that could control the progress of oral and pharyngeal cancers. In future studies, it is crucial to highlight the hypoxia role in the carcinogenesis of cancers of oral and pharynx.

Regarding xenobiotic biotransformation, the cyclooxygenase-2 (COX-2) biological function is known not only to evoke the inflammation response but also to participate in the progress of cooxidation [121]. COX-2, a prostaglandin synthase, is responsible for the xenobiotic metabolism and inflammation response. In the progress of head and neck cancer, elevated expression of COX-2 is well known to have a critical role via some biological pathways [122-124]. ANE modulated the enhancement of mRNA and protein expression of COX-2, showing important roles in BQ chewing related oral mucosal disorders $[42,125]$. A previous study indicated that BQ and its ingredients (arecoline/ANE) induced COX-2 expression in vitro [126]. Furthermore, the increased levels of COX-2 expression were found by using ANE and saliva-reacted ANE (sANE) treatments on three cell lines of oral epithelial carcinoma [19]. These results demonstrate an important insight into the potential effect of COX-2 and may contribute to the progress of BQ-related oral and pharyngeal cancers [19]. In BQ-related oral and pharyngeal cancers, upregulation of COX-2 can be promoted through a variety of upstream effectors. After a BQ/AN exposure, the upstream effectors may be released from the oral epithelial cells or oral microenvironment by linking to their corresponding sequences of COX-2 coding region or the promoter of COX-2 [19].

In proinflammatory and cancerous processes, the presence of two NF- $\kappa$ B binding sites close to the promoter of COX- 2 makes it very closely associated with NF- $\kappa$ B activation $[127,128]$. NF- $\kappa \mathrm{B}$ has been illustrated to be involved in the progress of tumorigenesis, and the expression of NF- $\kappa$ parallels COX-2 expression in OPMD, as well as oral and pharyngeal cancers [124]. NF- $\kappa \mathrm{B}$ signaling pathways involve classic NF- $\kappa \mathrm{B} 1$ and alternative NF- $\kappa \mathrm{B} 2$ on the proinflammatory regulators induction and $\mathrm{I} \kappa \mathrm{B}$ kinase complex activation [129]. Although the higher NF- $\kappa$ B2 mRNA expression may indicate that the alternative pathway plays a more critical role in the upregulation of COX-2, both signaling pathways of NF- $\kappa B$ may coexist in the BQ-induced activation of NF$\kappa \mathrm{B}$ on oral epithelial cells [19]. The NF- $\kappa \mathrm{B}$ activation and ROS formation were induced by ANE and NF- $\kappa$ B activation could be the foundation of the occurrence of ROS [117]. After treating ANE in OECM-1 and SAS oral keratinocytes, NF$\kappa \mathrm{B}$ and the mitogen-activated protein kinases activation have been indicated [130]. Also, ANE treatment may enhance the upregulation of COX-2 and NF- $\kappa$ B within normal human oral keratinocyte and is likely to associate with G1/S phase 
arrest of cell cycle and occurrence of cellular senescence [131]. Areca nut-derived arecoline can induce the expression of alphavbeta6 ( $\alpha \mathrm{v} \beta 6)$ integrin via the muscarinic acetylcholine receptor $\mathrm{M}(4)$ in oral keratinocyte [132].

Solid tumors are encircled by a specific tumor microenvironment that combines blood and lymphatic vessels, extracellular matrix, and mesenchymal and immune cells. The tumor microenvironment conducts many of the tumor aggression features, such as local metastasis and invasion. In tumor cells, tumor microenvironment can induce stem cell-like programs to form cancer stem cells which are known as cancer "stemness" [133]. Recent evidence indicates that cancer stem cells are responsible for the recurrence of tumors and are resistant to current common modes of treatment for cancer. A review article suggested that COX-2 triggers cancer stemness and support the maintenance of stem cells [134].

Overall, in oral cancer cells, ANE can induce oxidative stress, such as ROS, and upregulate hypoxia inducing factors leading to autophagy [117]. Although oral and pharyngeal cancers can be prevented and discovered early, the overall survival rate remains only about $50 \%$. Most oral and pharyngeal cancers may be formed through the progress of clinical lesions named OPMD. It is difficult to predict when the lesions transform into malignant ones and to provide appropriate strategies for their management. Understanding the molecular pathways involved will help us to prevent malignant transformation of OPMD and find useful strategies for early diagnosis and prevention of oral and pharyngeal cancers.

4.6. BQ Abuse/Addiction. BQ chewing has longstanding cultural and recreational importance in Asian and South Pacific communities. It is used in religious ceremonies and gatherings and forms a part of daily life in these regions $[3,135]$. Because of cultural traditions, its use is socially acceptable among all socioeconomic groups, even in women and young children $[5,136]$. These circumstances favor a sociocultural niche conducive for people to use and abuse this substance. However, to our knowledge, population data regarding BQ abuse and dependent use has not been available for the regions of Asia. Recently, the intercountry survey was initiated by BQ research groups of east, southeast, and southern Asia to investigate these issues [48]. Furthermore, tolerance and withdrawal syndromes to BQ were distinguished in habitual chewers $[8,135,137]$. Such neurobiological characteristics are analogous to those attributed to tobacco, a major psychoactive substance that can lead to misuse and dependence.

Currently, there are no accredited criteria for "BQ-mania" that lead to clinically significant BQ addiction-related disorders. The groups of Asian BQ consortium have developed a validated BQ addiction screening tool and scoring approach, and this effort elucidated the psychiatric aspects of BQ dependency (BQ-D) by understanding its sociodemographic, substance use, and environmental approachable heterogeneity undermining its population burden and health effects. In intercountry survey, the Taiwanese study revealed that the prevalence rates of BQ abuse in men (4.9\%) were higher than in women (1.7\%) [13]. In addition, we found a $46.0 \%$ BQ abuse rate in men current-chewers and a $68.8 \% \mathrm{BQ}$ abuse rate in women current-chewers in Taiwan using a validated BQabuser screening tool and scoring approach [13].

In an intercountry survey in Taiwan, the prevalence of BQ-D, defined independently through the criteria of the Diagnostic and Statistical Manual of Mental Disorders, Fourth Edition (DSM-IV), and International Statistical Classification of Diseases and Related Health Problems, 10th Revision (ICD-10), was higher among men (3.5\%-4.2\%) than among women $(1.1 \%)$, and the dependence rate in chewers was $41.7 \%$ for male chewers and $45.1 \%$ for female chewers [14]. One Indian study applied the criteria from DSM-IV-TR (Text Revision) to diagnose a substance use disorder along with the ICD-10 criteria for psychoactive substance use to define BQ-D and found that AN with or without tobacco are associated with the BQ-D syndrome development [135]. Our previous study suggested that alcohol usage was strongly related to BQ chewing in Taiwan aborigines [43]. To determine behavioral predictors of BQ chewing, 7144 aborigines were recruited into a community-based study in Taiwan. Habitual alcohol drinking was a significant factor associated with cessation of BQ use, while smoking had no statistical association with chewing BQ. Hence, efforts to abstain from alcohol might be effective in trying to quit the habit of BQ chewing [43].

4.7. The Mechanism for BQ Abuse/Addiction and Related Disorders In Vivo and In Vitro. BQ addiction and related disorders include BQ abuse, BQ dependence, and BQ abuse combined with $\mathrm{BQ}$ dependence. It is evident that $\mathrm{BQ}$ addiction has roots in complex behaviors; however, its precise biology is unknown. In rat brains, the dichloromethane fraction extracted from the areca palm (Areca catechu) of AN seed has antidepressant properties due to its inhibition of monoamine oxidase A (MAO-A) [138], but this is a very minor component of BQ and it is unknown whether it is consumed sufficiently among the styles of BQ chewing to affect the user. It is certain that the principle component of the $\mathrm{AN}$ is arecoline that passes through the blood-brain barrier $[139,140]$ and $\gamma$-amino-butyric acid (GABA) is a competitive inhibitor as well as an agonist to acetylcholine muscarinic receptors. As such, it has been reported to enhance acetylcholine levels in animal brains $[141,142]$ and inhibit the expression of MAO-A in male albino rats [143]. Thus, in the pathway of dopaminerich mesolimbic reward, it remains unclear whether arecoline could have a putative role by way of directly inhibiting MAOA or using acetylcholine as a proxy or inhibit GABAergic interneurons to enhance addiction similar to that in tobacco smoking and alcoholism [144].

Numerous susceptible genes are implicated in the mechanisms of addiction, and the optimal approach to selecting candidate genes is complicated. In spite of this, our study has hinted at the significance of the MAO-A gene (Xp 11.3) in heavy BQ use [145]. MAO catalyzes the deamination of biogenic amines, thus regulating synaptic levels of dopamine, serotonin, norepinephrine, and catecholaminergic neurotransmitters [144] to influence addictive behaviors, motor, memory, and mood [146]. Because MAO-A has been involved in the dopaminergic tone modulation to facilitate reinforcing 
behaviors [147], this provides a likely addiction framework for BQ chewing. In animal brains, arecoline has been found to enhance cortical dopamine. In these studies, 15 minutes after the administration of arecoline, a reduction in the levels of acetylcholine and norepinephrine was observed [148]. Recently, study findings suggested increased dopamine levels are likely derived, at least in part, from MAO-A inhibition [145]. Additionally, the amount of 6 different neurotransmitters was determined in rat brains using LC-MS-MS [149].

Our recent results showed that direct treatment of neuroblastoma cells with ANE and arecoline progressively inhibited MAO-A in a dose-dependent manner; this was measured via microarray and confirmed by qRT-PCR and in vivo rat studies [145]. In experimental animals, conditioned place preference (CPP) is one of the most common methods to evaluate nondrug therapy and the motivational effects of drugs and to quantify drug reward in laboratory animals [150]. The CPP model is conducted to explore the reinforcing properties of drug abuse and maladaptive behaviors progress. In a previous study, the CPP paradigm was used to observe the role of candidate genes in the progress of substanceinduced CPP [151].

In human psychopharmacology researches, positron emission tomography (PET) and single photon emission computed tomography (SPECT) have been designed as increasingly effective imaging tools during the last two decades. PET and SPECT have been established to enhance pharmacokinetics and pharmacodynamics of substance addiction and have created many contributions in terms of addiction mechanisms [152]. In the [11C] befloxatone study, PET indicated that the cerebral MAO-A inhibition caused by components of cigarette smoke could be involved in tobacco addiction [153]. The role of the striatal dopamine system has been thought to encompass circuits that are involved in the coordination of motor [154]. A recent study has involved this system in the responses of reward and cognitive activities integration and by the human corticostriatothalamic systems [155]. Dopamine transporter (DAT) is one of the crucial presynaptic factors complicated in modulating dopaminergic tone. Some imaging studies also reported that availability of striatal DAT was prominently related to the functional impact of mood regulation, various cognitive actions, and complicated social behavior by using SPECT with [99mTc] TRODAT-1 (a radio-labeled form of tropane derivative for the selective labeling of DAT) [156158].

4.8. MAO-A Variants Associated with Increased BQ Use. In Taiwan aborigines, our previous results provided a novel finding that variants of MAO-A were significantly related to the behaviors of heavy BQ consumption. Genetic polymorphism of MAO-A single-nucleotide polymorphisms (SNPs) in both men $(\mathrm{OR}=2.04$ for $\mathrm{rs} 2283725 ; \mathrm{OR}=2.03$ for rs5953210) and women (OR = 1.54 for rs2283725; OR = 1.59 for rs5953210) appeared to correlate with a higher likelihood of heavy $\mathrm{BQ}$ chewing. Compared with nonusers, the MAO-A activity was significantly higher among BQ users. This effect was enhanced strongly with alcohol use. Subjects with specific $M A O-A$ polymorphisms that have a higher enzyme activity of MAO-A predispose to BQ abuse liability among Taiwan aborigines [145].

4.9. BQ Abuse-Related MAO Variants May Be Related to the Risk of BQ-Associated Oral and Pharyngeal Cancers. The occurrence of oral and pharyngeal cancers is implicated in a joint effect between exposure of environmental factors (e.g., alcohol, BQ, and cigarette) and gene expression. A microarray study conducted by our group found that $\mathrm{BQ}$ and its components (ANE/arecoline) induced the expression of addiction-related $\mathrm{MAO}$ genes in vitro. Our previous studies suggested that MAO-A and monoamine oxidase $\mathrm{B}$ (MAOB) variants are associated with oral and pharyngeal cancer risks [159]. We confirmed that downregulation of MAO-A and MAO-B gene was more prominent in oral and pharyngeal cancerous tissues than in their adjacent noncancerous tissues. Moreover, we demonstrated that BQ chewing and MAO-A polymorphisms are linked with oral and pharyngeal cancers [145]. The single-nucleotide polymorphism variants of MAO-A were significantly related to patients with oral and pharyngeal cancers in comparison to patients with OPMD (risk G-allele for rs5953210, OR $=1.76 ; 95 \% \mathrm{CI}=1.02-3.01$ ) [145]. Therefore, these results provide a crucial insight into the potential impact of $\mathrm{MAO}$ variants in contributing to the occurrence of BQ-related oral and pharyngeal cancers.

The above results will provide new insights into the behavior of BQ use and related oral and pharyngeal cancers and other disorders. The strong implication of high $\mathrm{BQ}$ exposure in the development of $\mathrm{BQ}$ addiction and related disorders indicates that our country must become more aware of this issue. As is illustrated above, an association of BQ exposure with BQ-related disorders has been shown in humans. Studies of complex traits such as the occurrence of oral and pharyngeal cancers should incorporate both genetic and environmental factors. In the future, we must study the association between BQ-related disorders and the expression of two susceptibility genes $(M A O-A / M A O-B)$ related to $\mathrm{BQ}$ pathways or neurotransmitter metabolism. Alkaloids, the active metabolic compounds of $\mathrm{BQ}$, can interact with neurotransmitters and susceptibility genes to exacerbate BQrelated disorders.

4.10. The Draft of BQ Withdrawal Policy with Taiwan as an Example. In the Ministry of Health and Welfare (MOHW), Taiwan, the buzzword is "ABC 123" for health education indicating that the synergistic joint effects of alcohol (A), BQ (B), and cigarette (C) enhance 123-fold risk for the occurrence of oral cancer. The 123-fold risk was obtained from a highly cited paper [10], and this paper has already been cited more than 440 times [10]. According to these results, MOHW established "the prevention day of BQ" in December (12), 3, every year. These efforts promoted the management policy of our government and help to enhance the strategy of "BQ Education." At present, the BQ researchers and epidemiologists have become prominent in Taiwan. BQ chewing is strongly related to alcohol drinking and/or smoking, and preventive policies should be concentrated on the cessation pattern of BQ chewing and the related individual habits of alcohol and tobacco use. 
The area of human health effects of group 1 carcinogens, such as BQ, has been identified as an important research topic in Taiwan. Future research should aim to fill gaps in our knowledge concerning the effect of BQ abuse/dependent use on health consequences in Taiwanese communities. BQ addiction and the associated high prevalence of oral and pharyngeal cancers in Taiwan also highlight the uniqueness and health relevance of this review article. Our efforts can provide an effective methodology to reduce the rates of $B Q$ chewing. Therefore, these effects have enhanced the management policy of our government and helped to promote the strategy of "Outpatient Services for BQ Screening and Cessation."

A decreasing amount of BQ consumption is being observed in Taiwan after continuing the strategies of successive health promotion. In 2008, the Bureau of Health Promotion of MOHW assigned a BQ cessation plan to us for exploring specific exposure indicators among chewers and entitled this project "specific biomarkers of chewing behavior and cessation patterns among BQ chewers" [15]. Recently, an intercountry study indicated that Taiwanese men have a higher quit rate (31.1\%) than other countries, and this may be a result of effective $B Q$ prevention activities and interventions [48]. In conclusion, we believe that these endeavors may offer effective strategies of public health against BQ chewing related health effects.

\section{Conclusion}

This review provides important insights regarding the potential role of environmental BQ in the occurrence and progress of oral and pharyngeal cancers and related risks of human health. Subsequent molecular mechanisms and pharmacokinetics studies will establish a stable foundation for the prevention, clinical diagnosis, and treatment effectiveness of BQ addiction-related disorders.

\section{Conflicts of Interest}

The authors declare no conflicts of interest regarding the publication of this paper.

\section{Acknowledgments}

This study was supported by a grant from the Kaohsiung Medical University Research Foundation (KMU-M106020), a grant from the Center for Infectious Disease and Cancer Research, Kaohsiung Medical University (KMU-TP104E26), a grant from Kaohsiung Medical University Research Foundation (105KMUOR02), and grants from the Health and Welfare Surcharge of Tobacco Products, the Ministry of Health and Welfare, Taiwan, Republic of China (MOHW106TDU-B-212-144007 and MOHW106-TDU-B-212-122016).

\section{References}

[1] R. J. Sullivan and E. H. Hagen, "Psychotropic substance-seeking: Evolutionary pathology or adaptation?” Addiction, vol. 97, no. 4, pp. 389-400, 2002.
[2] P. C. Gupta and C. S. Ray, "Epidemiology of betel quid usage," Annals of the Academy of Medicine, Singapore, vol. 33, no. 4, supplement, pp. 31-36, 2004.

[3] P. C. Gupta and S. Warnakulasuriya, "Global epidemiology of areca nut usage," Addiction Biology, vol. 7, no. 1, pp. 77-83, 2002.

[4] S. Tovosia, P. H. Chen, A. M. Ko, H. P. Tu, P. C. Tsai, and Y. C. Ko, "Prevalence and associated factors of betel quid use in the Solomon Islands: a hyperendemic area for oral and pharyngeal cancer," The American Journal of Tropical Medicine and Hygiene, vol. 77, no. 3, pp. 586-590, 2007.

[5] J. Changrani and F. Gany, "Paan and gutka in the United States: an emerging threat," Journal of Immigrant Health, vol. 7, no. 2, pp. 103-108, 2005.

[6] N.-S. Chu, "Effects of Betel chewing on the central and autonomic nervous systems," Journal of Biomedical Science, vol. 8, no. 3, pp. 229-236, 2001.

[7] A. Winstock, "Areca nut-abuse liability, dependence and public health," Addiction Biology, vol. 7, no. 1, pp. 133-138, 2002.

[8] A. R. Winstock, C. R. Trivedy, K. A. A. S. Warnakulasuriya, and T. J. Peters, "A dependency syndrome related to areca nut use: some medical and psychological aspects among areca nut users in the Gujarat community in the UK," Addiction Biology, vol. 5, no. 2, pp. 173-179, 2000.

[9] World Health Organization and International Agency for Research on Cancer (IARC), Betel-Quid and Areca-Nut Chewing and Some Areca-Nut-Derived Nitrosamines, vol. 85 of IARC Monographs on the Evaluation of Carcinogenic Risks to Humans, 2004.

[10] Y. C. Ko, Y. L. Huang, C. H. Lee, M. J. Chen, L. M. Lin, and C. C. Tsai, "Betel quid chewing, cigarette smoking and alcohol consumption related to oral cancer in Taiwan," Journal of Oral Pathology \& Medicine, vol. 24, no. 10, pp. 450-453, 1995.

[11] P. H. Chen, K. W. Lee, C. H. Chen et al., "CYP26B1 is a novel candidate gene for betel quid-related oral squamous cell carcinoma," Oral Oncology, vol. 47, no. 7, pp. 594-600, 2011.

[12] K. W. Lee, W. R. Kuo, S. M. Tsai et al., "Different impact from betel quid, alcohol and cigarette: risk factors for pharyngeal and laryngeal cancer," International Journal of Cancer, vol. 117, no. 5, pp. 831-836, 2005.

[13] C.-H. Lee, A. M.-S. Ko, S. Warnakulasuriya et al., "Population burden of betel quid abuse and its relation to oral premalignant disorders in South, Southeast, and East Asia: An Asian BetelQuid Consortium study," American Journal of Public Health, vol. 102, no. 3, pp. el7-e24, 2012.

[14] C.-H. Lee, A. M.-S. Ko, C.-F. Yen et al., "Betel-quid dependence and oral potentially malignant disorders in six Asian countries," The British Journal of Psychiatry, vol. 201, no. 5, pp. 383-391, 2012.

[15] I. C. Wu, P. H. Chen, C. J. Wang et al., "Quantification of blood betel quid alkaloids and urinary 8-hydroxydeoxyguanosine in humans and their association with betel chewing habits," Journal of Analytical Toxicology, vol. 34, no. 6, pp. 325-331, 2010.

[16] A. Nishikawa, B. Prokopczyk, A. Rivenson, E. Zang, and D. Hoffmann, "A study of betel quid carcinogenesis-VIII. Carcinogenicity of 3-(methylnitrosamino)propionaldehyde in f344 rats," Carcinogenesis, vol. 13, no. 3, pp. 369-372, 1992.

[17] D. Hoffmann, K. D. Brunnemann, B. Prokopczyk, and M. V. Djordjevic, "Tobacco-specific N-nitrosamines and Arecaderived N-nitrosamines: chemistry, biochemistry, carcinogenicity, and relevance to humans," Journal of Toxicology and Environmental Health, vol. 41, no. 1, pp. 1-52, 1994. 
[18] C.-H. Lee, Y.-C. Ko, H.-L. Huang et al., "The precancer risk of betel quid chewing, tobacco use and alcohol consumption in oral leukoplakia and oral submucous fibrosis in southern Taiwan," British Journal of Cancer, vol. 88, no. 3, pp. 366-372, 2003.

[19] S. L. Chiang, P. H. Chen, C. H. Lee et al., "Up-regulation of inflammatory signalings by areca nut extract and role of cyclooxygenase-2 -1195G\&\#62;a polymorphism reveal risk of oral cancer," Cancer Research, vol. 68, no. 20, pp. 8489-8498, 2008.

[20] C. H. Lee, K. W. Lee, F. M. Fang et al., "The use of tobacco-free betel-quid in conjunction with alcohol/tobacco impacts earlyonset age and carcinoma distribution for upper aerodigestive tract cancer," Journal of Oral Pathology \& Medicine, vol. 40, no. 9, pp. 684-692, 2011.

[21] I. C. Wu, C. Y. Lu, F. C. Kuo et al., "Interaction between cigarette, alcohol and betel nut use on esophageal cancer risk in Taiwan," European Journal of Clinical Investigation, vol. 36, no. 4, pp. 236241, 2006.

[22] J. F. Tsai, L. Y. Chuang, J. E. Jeng et al., "Betel quid chewing as a risk factor for hepatocellular carcinoma: A case-control study," British Journal of Cancer, vol. 84, no. 5, pp. 709-713, 2001.

[23] J.-F. Tsai, J.-E. Jeng, L.-Y. Chuang et al., "Habitual betel quid chewing and risk for hepatocellular carcinoma complicating cirrhosis," Medicine, vol. 83, no. 3, pp. 176-187, 2004.

[24] J.-E. Jeng, M.-F. Tsai, H.-R. Tsai et al., "Impact of chronic hepatitis B and hepatitis $\mathrm{C}$ on adverse hepatic fibrosis in hepatocellular carcinoma related to betel quid chewing," Asian Pacific Journal of Cancer Prevention, vol. 15, no. 2, pp. 637-642, 2014.

[25] J.-F. Tsai, J.-E. Jeng, L.-Y. Chuang et al., "Habitual betel quid chewing as a risk factor for cirrhosis: A case-control study," Medicine, vol. 82, no. 5, pp. 365-372, 2003.

[26] A. M. Yen, Y. H. Chiu, L. S. Chen et al., "A population-based study of the association between betel-quid chewing and the metabolic syndrome in men," The American Journal of Clinical Nutrition, vol. 83, no. 5, pp. 1153-1160, 2006.

[27] J. Y. Guh, L. Y. Chuang, and H. C. Chen, "Betel-quid use is associated with the risk of the metabolic syndrome in adults," The American Journal of Clinical Nutrition, vol. 83, no. 6, pp. 1313-1320, 2006.

[28] T.-H. Tung, Y.-H. Chiu, L.-S. Chen, H.-M. Wu, B. J. Boucher, and T. H.-H. Chen, "A population-based study of the association between areca nut chewing and Type 2 diabetes mellitus in men (Keelung Community-based Integrated Screening programme No. 2)," Diabetologia, vol. 47, no. 10, pp. 1776-1781, 2004.

[29] J. E. Heck, E. L. Marcotte, M. Argos et al., "Betel quid chewing in rural Bangladesh: prevalence, predictors and relationship to blood pressure," International Journal of Epidemiology, vol. 41, no. 2, pp. 462-471, 2012.

[30] W. Y. Lin, T. Y. Chiu, L. T. Lee, C. C. Lin, C. Y. Huang, and K. C. Huang, "Betel nut chewing is associated with increased risk of cardiovascular disease and all-cause mortality in Taiwanese men," The American Journal of Clinical Nutrition, vol. 87, no. 5, pp. 1204-1211, 2008.

[31] A. M.-F. Yen, L.-S. Chen, Y.-H. Chiu, B. J. Boucher, and T. H.H. Chen, "A prospective community-population-registry-based cohort study of the association between betel-quid chewing and cardiovascular disease in men in Taiwan (KCIS no. 19)," American Journal of Clinical Nutrition, vol. 87, no. 1, pp. 70-78, 2008.
[32] J. Y. Guh, H. C. Chen, J. F. Tsai, and L. Y. Chuang, "Betel-quid use is associated with heart disease in women," The American Journal of Clinical Nutrition, vol. 85, no. 5, pp. 1229-1235, 2007.

[33] C.-Y. Chou, S.-Y. Cheng, J.-H. Liu et al., "Association between betel-nut chewing and chronic kidney disease in men," Public Health Nutrition, vol. 12, no. 5, pp. 723-727, 2009.

[34] F. Wu, F. Parvez, T. Islam et al., "Betel quid use and mortality in Bangladesh: A cohort study," Bulletin of the World Health Organization, vol. 93, no. 10, pp. 684-692, 2015.

[35] T.-Y. Lan, W.-C. Chang, Y.-J. Tsai, Y.-L. Chuang, H.-S. Lin, and T.-Y. Tai, "Areca nut chewing and mortality in an elderly cohort study," American Journal of Epidemiology, vol. 165, no. 6, pp. 677-683, 2007.

[36] M. Ome-Kaius, H. W. Unger, D. Singirok et al., "Determining effects of areca (betel) nut chewing in a prospective cohort of pregnant women in Madang Province, Papua New Guinea," BMC Pregnancy and Childbirth, vol. 15, no. 1, article 177, 2015.

[37] M.-S. Yang, C.-H. Lee, S.-J. Chang et al., "The effect of maternal betel quid exposure during pregnancy on adverse birth outcomes among aborigines in Taiwan," Drug and Alcohol Dependence, vol. 95, no. 1-2, pp. 134-139, 2008.

[38] M.-S. Yang, T.-C. Chung, M.-J. Yang, T.-Y. Hsu, and Y.-C. Ko, "Betel quid chewing and risk of adverse birth outcomes among aborigines in eastern Taiwan," Journal of Toxicology and Environmental Health, Part A. Current Issues, vol. 64, no. 6, pp. 465-472, 2001.

[39] R. F. H. Taylor, N. Al-Jarad, L. M. E. John, D. M. Conroy, and N. C. Barnes, "Betel-nut chewing and asthma," The Lancet, vol. 339, no. 8802, pp. 1134-1136, 1992.

[40] T.-N. Wang, M.-S. Huang, M.-C. Lin et al., "Betel chewing and arecoline affects eotaxin-1, asthma and lung function," PLoS ONE, vol. 9, no. 3, Article ID e91889, 2014.

[41] L.-Y. Wang, S.-L. You, S.-N. Lu et al., "Risk of hepatocellular carcinoma and habits of alcohol drinking, betel quid chewing and cigarette smoking: A cohort of $2416 \mathrm{HBsAg}$-seropositive and $9421 \mathrm{HBsAg-seronegative} \mathrm{male} \mathrm{residents} \mathrm{in} \mathrm{Taiwan,"} \mathrm{Can-}$ cer Causes \& Control, vol. 14, no. 3, pp. 241-250, 2003.

[42] M.-S. Yang, F.-T. Chang, S.-S. Chen, C.-H. Lee, and Y.-C. Ko, "Betel quid chewing and risk of adverse pregnancy outcomes among aborigines in Southern Taiwan," Public Health, vol. 113, no. 4, pp. 189-192, 1999.

[43] C.-F. Lin, J.-D. Wang, P.-H. Chen, S.-J. Chang, Y.-H. Yang, and Y.-C. Ko, "Predictors of betel quid chewing behavior and cessation patterns in Taiwan aborigines," BMC Public Health, vol. 6, article 271, 2006.

[44] S.-H. Lin, Y.-S. Liao, S.-H. Huang, and W.-H. Liao, "Relationship between betel quid chewing and risks of cardiovascular disease in older adults: A cross-sectional study in Taiwan," Drug and Alcohol Dependence, vol. 141, pp. 132-137, 2014.

[45] T. Yamada, K. Hara, and T. Kadowaki, "Chewing betel quid and the risk of metabolic disease, cardiovascular disease, and all-cause mortality: a meta-analysis," PLoS ONE, vol. 8, no. 8, Article ID e70679, 2013.

[46] R. J. Sullivan, J. S. Allen, C. Otto, J. Tiobech, and K. Nero, "Effects of chewing betel nut (Areca catechu) on the symptoms of people with schizophrenia in Palau, Micronesia," The British Journal of Psychiatry, vol. 177, pp. 174-178, 2000.

[47] R. J. Sullivan, S. Andres, C. Otto, W. Miles, and R. Kydd, "The effects of an indigenous muscarinic drug, betel nut (Areca catechu), on the symptoms of schizophrenia: A longitudinal study in Palau, Micronesia," The American Journal of Psychiatry, vol. 164, no. 4, pp. 670-673, 2007. 
[48] C. H. Lee, A. M. Ko, S. Warnakulasuriya et al., "Intercountry prevalences and practices of betel-quid use in south, southeast and eastern asia regions and associated oral preneoplastic disorders: an international collaborative study by asian betelquid consortium of south and east Asia," International Journal of Cancer, vol. 129, no. 7, pp. 1741-1751, 2011.

[49] P. A. Reichart, U. Mohr, S. Srisuwan, H. Geerlings, C. Theetranont, and T. Kangwanpong, "Precancerous and other oral mucosal lesions related to chewing, smoking and drinking habits in Thailand," Community Dentistry and Oral Epidemiology, vol. 15, no. 3, pp. 152-160, 1987.

[50] D. N. Sinha, P. C. Gupta, C. Ray, and P. K. Singh, "Prevalence of smokeless tobacco use among adults in WHO South-East Asia," Indian Journal of Cancer, vol. 49, no. 4, pp. 342-346, 2012.

[51] P. A. Reichart and T. H. Way, "Oral cancer and pre-cancer in Myanmar: a short review," Journal of Oral Pathology \& Medicine, vol. 35, no. 4, pp. 193-196, 2006.

[52] K.-K. Zaw, M. Ohnmar, M.-M. Hlaing et al., "Betel quid and oral potentially malignant disorders in a periurban township in Myanmar," PLoS ONE, vol. 11, no. 9, Article ID e0162081, 2016.

[53] P. A. Reichart and X. H. Nguyen, "Betel quid chewing, oral cancer and other oral mucosal diseases in Vietnam: A review," Journal of Oral Pathology \& Medicine, vol. 37, no. 9, pp. 511-514, 2008.

[54] S. S. Strickland and A. E. Duffield, "Anthropometric status and resting metabolic rate in users of the areca nut and smokers of tobacco in rural Sarawak," Annals of Human Biology, vol. 24, no. 5, pp. 453-474, 1997.

[55] S. S. Strickland and A. E. Duffield, "Nutrition and ecosystems in Sarawak: the role of the areca nut," Asia Pacific Journal of Clinical Nutrition, vol. 7, no. 3-4, pp. 300-306, 1998.

[56] B. S. Tan, A. Rosman, K. H. Ng, and N. Ahmad, "Profile of the betel/tobacco quid chewers in six Malaysian estates," Annals of Dentistry, University of Malaya, vol. 7, pp. 1-5, 2000.

[57] W. M. N. Ghani, I. A. Razak, Y.-H. Yang et al., "Factors affecting commencement and cessation of betel quid chewing behaviour in Malaysian adults," BMC Public Health, vol. 11, article 82, 2011.

[58] N. Ikeda, Y. Handa, S. P. Khim et al., "Prevalence study of oral mucosal lesions in a selected Cambodian population," Community Dentistry and Oral Epidemiology, vol. 23, no. 1, pp. 49-54, 1995.

[59] T. Chher, S. Hak, T. G. Kallarakkal et al., "Prevalence of oral cancer, oral potentially malignant disorders and other oral mucosal lesions in Cambodia," Ethnicity \& Health, pp. 1-15, 2016.

[60] P. C. Gupta, "Survey of sociodemographic characteristics of tobacco use among 99,598 individuals in Bombay, India using handheld computers," Tobacco Control, vol. 5, no. 2, pp. 114-120, 1996.

[61] P. C. Gupta and C. S. Ray, "Areca nut use and cancer in India," Biomedical Research International, vol. 2, no. 2, pp. 140-165, 2015.

[62] Z. Mahmood, N. A. Jaferey, M. Samiuddin, S. Malik, and S. A. Qureshi, "Dietary and other habits of people of Karachi," Journal of Pakistan Medical Association, vol. 26, pp. 222-229, 1974.

[63] S. Mazahir, R. Malik, M. Maqsood et al., "Socio-demographic correlates of betel, areca and smokeless tobacco use as a high risk behavior for head and neck cancers in a squatter settlement of Karachi, Pakistan," Substance Abuse Treatment, Prevention, and Policy, vol. 1, no. 1, article 10, 2006.
[64] N. Nisar, M. H. Qadri, K. Fatima, and S. Perveen, "A community based study about knowledge and practices regarding tobacco Consumption and passive smoking in Gadap Town, Karachi," Journal of the Pakistan Medical Association, vol. 57, no. 4, pp. 186-188, 2007.

[65] F. Tanwir, M. Altamash, and A. Gustafsson, "Influence of betel nut chewing, dental care habits and attitudes on perceived oral health among adult Pakistanis," Oral Health \& Preventive Dentistry, vol. 6, no. 2, pp. 89-94, 2008.

[66] K. A. A. S. Warnakulasuriya, "Smoking and chewing habits in Sri Lanka: implications for oral cancer and precancer," in Control of Tobacco-Related Cancers and Other Diseases, P. C. Gupta, J. E. Hamner III, and P. R. Murti, Eds., pp. 113-118, Oxford University Press, Mumbai, India, 1992.

[67] Y. C. Ko, T. A. Chiang, S. J. Chang, and S. F. Hsieh, "Prevalence of betel quid chewing habit in Taiwan and related sociodemographic factors," Journal of Oral Pathology \& Medicine, vol. 21, no. 6, pp. 261-264, 1992.

[68] C. P. Wen, S. P. Tsai, T. Y. Cheng et al., "Uncovering the relation between betel quid chewing and cigarette smoking in Taiwan," Tobacco Control, vol. 14, supplement 1, pp. i16-i22, 2005.

[69] C. H. Chung, Y. H. Yang, T. Y. Wang, T. Y. Shieh, and S. Warnakulasuriya, "Oral precancerous disorders associated with areca quid chewing, smoking, and alcohol drinking in southern Taiwan," Journal of Oral Pathology \& Medicine, vol. 34, no. 8, pp. 460-466, 2005.

[70] S.-F. Yap, P.-S. Ho, H.-C. Kuo, and Y.-H. Yang, "Comparing factors affecting commencement and cessation of betel quid chewing behavior in Taiwanese adults," BMC Public Health, vol. 8, article 199, 2008.

[71] J.-G. Tang, X.-F. Jian, M.-L. Gao, T.-Y. Ling, and K.-H. Zhang, "Epidemiological survey of oral submucous fibrosis in Xiangtar City, Hunan Province, China," Community Dentistry and Oral Epidemiology, vol. 25, no. 2, pp. 177-180, 1997.

[72] J. J. Pindborg, D. O. D. Barmes, and B. Roed-Petersen, "Epidemiology and histology of oral leukoplakia and leukoedema among Papuans and New Guineans," Cancer, vol. 22, no. 2, pp. 379-384, 1968.

[73] S. J. Thomas, C. J. Bain, D. Battistutta, A. R. Ness, D. Paissat, and R. Maclennan, "Betel quid not containing tobacco and oral cancer: A report on a case-control study in Papua New Guinea and a meta-analysis of current evidence," International Journal of Cancer, vol. 120, no. 6, pp. 1318-1323, 2007.

[74] S. J. Thomas, R. Harris, A. R. Ness et al., "Betel quid not containing tobacco and oral leukoplakia: A report on a crosssectional study in Papua New Guinea and a meta-analysis of current evidence," International Journal of Cancer, vol. 123, no. 8, pp. 1871-1876, 2008.

[75] J. Ysaol, J. I. Chilton, and P. Callaghan, "A survey of betel nut chewing in Palau," ISLA Journal of Micronesian Studies, vol. 4, pp. 244-255, 1996.

[76] GLOBOCAN 2012: Estimated Cancer Incidence, Mortality and Prevalence worlwide in 2012, International Agency for Research on Cancer, Word Health Organization, 2017, http://globocan iarc.fr/Default.aspx.

[77] Ministry of Health and Welfare, "Cancer registration system annual report, Taiwan,” Tech. Rep., 2012.

[78] K. A. L. A. Kuruppuarachchi and S. S. Williams, "Betel use and schizophrenia," The British Journal of Psychiatry, vol. 182, no. 5, p. 455, 2003.

[79] A. Bales, M. J. Peterson, S. Ojha, K. Upadhaya, B. Adhikari, and B. Barrett, "Associations between betel nut (Areca catechu) 
and symptoms of schizophrenia among patients in Nepal: a longitudinal study," Psychiatry Research, vol. 169, no. 3, pp. 203211, 2009.

[80] P.-F. Wu, T.-A. Chiang, M.-T. Chen et al., "A characterization of the antioxidant enzyme activity and reproductive toxicity in male rats following sub-chronic exposure to areca nut extracts," Journal of Hazardous Materials, vol. 178, no. 1-3, pp. 541-546, 2010.

[81] Ministry of Health and Welfare, "Cancer registration system annual report, Taiwan,” Tech. Rep., 2014.

[82] Ministry of Health and Welfare, "Cancer registration system annual report, Taiwan," Taiwan, 2004-2014.

[83] Y. H. Yang, H. Y. Lee, S. Tung, and T. Y. Shieh, "Epidemiological survey of oral submucous fibrosis and leukoplakia in aborigines of Taiwan," Journal of Oral Pathology \& Medicine, vol. 30, no. 4, pp. 213-219, 2001.

[84] M. S. Yang, I. H. Su, J. K. Wen, and Y. C. Ko, "Prevalence and related risk factors of betel quid chewing by adolescent students in southern Taiwan," Journal of Oral Pathology \& Medicine, vol. 25, no. 2, pp. 69-71, 1996.

[85] Y. K. Chen, H. C. Huang, L. M. Lin, and C. C. Lin, "Primary oral squamous cell carcinoma: an analysis of 703 cases in southern Taiwan," Oral Oncology, vol. 35, no. 2, pp. 173-179, 1999.

[86] P.-H. Chen, Y.-C. Ko, Y.-H. Yang et al., "Important prognostic factors of long-term oropharyngeal carcinoma survivors in Taiwan," Oral Oncology, vol. 40, no. 8, pp. 847-855, 2004.

[87] P.-H. Chen, T.-Y. Shieh, P.-S. Ho et al., "Prognostic factors associated with the survival of oral and pharyngeal carcinoma in Taiwan," BMC Cancer, vol. 7, article 101, 2007.

[88] C. Mougne, R. MacLennan, and S. Atsana, "Smoking, chewing and drinking in Ban Pong, Northern Thailand," Social Science \& Medicine, vol. 16, no. 1, pp. 99-106, 1982.

[89] P. A. Reichart, "Oral cancer and precancer related to betel and miang chewing in Thailand: A review," Journal of Oral Pathology \& Medicine, vol. 24, no. 6, pp. 241-243, 1995.

[90] J. Ferlay, F. Bray, P. Pisani, and D. M. Parkin, Globocan 2012, Cancer Incidence, Mortality and Prevalence Worlwide, IARC, Lyon, France, 2003.

[91] J. Ferlay, F. Bray, P. Pisani, and D. M. Parkin, Globocan 2002, Cancer Incidence, Mortality and Prevalence Worlwide, IARC, Lyon, France, 2003.

[92] X. Zhang and P. A. Reichart, "A review of betel quid chewing, oral cancer and precancer in Mainland China," Oral Oncology, vol. 43 , no. 5 , pp. 424-430, 2007.

[93] M. C. Chang, Y. S. Ho, P. H. Lee et al., "Areca nut extract and arecoline induced the cell cycle arrest but not apoptosis of cultured oral KB epithelial cells: Association of glutathione, reactive oxygen species and mitochondrial membrane potential," Carcinogenesis, vol. 22, no. 9, pp. 1527-1535, 2001.

[94] K. Sundqvist, Y. Liu, J. Nair, H. Bartsch, K. Arvidson, and R. C. Grafstrom, "Cytotoxic and genotoxic effects of areca nut-related compounds in cultured human buccal epithelial cells," Cancer Research, vol. 49, no. 19, pp. 5294-5298, 1989.

[95] J. H. Jeng, M. Y. P. Kuo, L. J. Hahn, and M. L. Kuo, "Genotoxic and non-genotoxic effects of betel quid ingredients on oral mucosal fibroblasts in vitro," Journal of Dental Research, vol. 73, no. 5, pp. 1043-1049, 1994.

[96] J. H. Jeng, W. H. Lan, L. J. Hahn, C. C. Hsieh, and M. Y. Kuo, "Inhibition of the migration, attachment, spreading, growth and collagen synthesis of human gingival fibroblasts by arecoline, a major areca alkaloid, in vitro," Journal of Oral Pathology \& Medicine, vol. 25, no. 7, pp. 371-375, 1996.
[97] J.-H. Jeng, L.-J. Hahn, B.-R. Lin, C.-C. Hsieh, C.-P. Chan, and M.-C. Chang, "Effects of areca nut, inflorescence piper betle extracts and arecoline on cytotoxicity, total and unscheduled DNA synthesis in cultured gingival keratinocytes," Journal of Oral Pathology \& Medicine, vol. 28, no. 2, pp. 64-71, 1999.

[98] J. H. Jeng, M. C. Chang, and L. J. Hahn, "Role of areca nut in betel quid-associated chemical carcinogenesis: current awareness and future perspectives," Oral Oncology, vol. 37, no. 6, pp. 477-492, 2001.

[99] G. A. Lord, C. K. Lim, S. Warnakulasuriya, and T. J. Peters, "Chemical and analytical aspects of areca nut," Addiction Biology, vol. 7, no. 1, pp. 99-102, 2002.

[100] C.-J. Chou, H.-M. Su, H.-H. Lee, Y.-C. Ko, P.-H. Chen, and B.-H. Chen, "Life-threatening cardiac toxicity after chewing inverted nut (Pinang-Wang)," Annals of Emergency Medicine, vol. 54, no. 5, pp. 757-758, 2009.

[101] U. J. Nair, M. Friesen, I. Richard, R. Maclennan, S. Thomas, and H. Bartsch, "Effect of lime composition on the formation of reactive oxygen species from areca nut extract in vitro," Carcinogenesis, vol. 11, no. 12, pp. 2145-2148, 1990.

[102] U. J. Nair, R. A. Floyd, J. Nair, V. Bussachini, M. Friesen, and $\mathrm{H}$. Bartsch, "Formation of reactive oxygen species and of 8-hydroxydeoxyguanosine in DNA in vitro with betel quid ingredients," Chemico-Biological Interactions, vol. 63, no. 2, pp. 157-169, 1987.

[103] U. J. Nair, G. Obe, M. Friesen, M. T. Goldberg, and H. Bartsch, "Role of lime in the generation of reactive oxygen species from betel-quid ingredients," Environmental Health Perspectives, vol. 98, pp. 203-205, 1992.

[104] U. J. Nair, J. Nair, M. D. Friesen, H. Bartsch, and H. Ohshima, "Ortho- and meta-tyrosine formation from phenylalanine in human saliva as a marker of hydroxyl radical generation during betel quid chewing," Carcinogenesis, vol. 16, no. 5, pp. 1195-1198, 1995.

[105] H. F. Stich and F. Anders, "The involvement of reactive oxygen species in oral cancers of betel quid/tobacco chewers," Mutation Research, vol. 214, no. 1, pp. 47-61, 1989.

[106] U. Nair, H. Bartsch, and J. Nair, "Alert for an epidemic of oral cancer due to use of the betel quid substitutes gutkha and pan masala: a review of agents and causative mechanisms," Mutagenesis, vol. 19, no. 4, pp. 251-262, 2004.

[107] T. Liu, C. Chen, and C. Chi, "Oxidative damage to DNA induced by areca nut extract," Mutation Research, vol. 367, no. 1, pp. 2531, 1996.

[108] C.-L. Chen, C.-W. Chi, and T.-Y. Liu, "Hydroxyl radical formation and oxidative DNA damage induced by areca quid in vivo," Journal of Toxicology and Environmental Health, Part A. Current Issues, vol. 65, no. 3-4, pp. 327-336, 2002.

[109] P. Chen, C. Tsai, Y. Lin et al., "Ingredients contribute to variation in production of reactive oxygen species by areca quid," Journal of Toxicology and Environmental Health, Part A. Current Issues, vol. 69, no. 11, pp. 1055-1069, 2006.

[110] D. E. G. Shuker and P. B. Farmer, "Relevance of urinary DNA adducts as markers of carcinogen exposure," Chemical Research in Toxicology, vol. 5, no. 4, pp. 450-460, 1992.

[111] S. J. Thomas and R. MacLennan, "Slaked lime and betel nut cancer in Papua New Guinea," The Lancet, vol. 340, no. 8819, pp. 577-578, 1992.

[112] H. Ernst, H. Ohshima, H. Bartsch, U. Mohr, and P. Reichart, "Tumorigenicity study in syrian hamsters fed areca nut together with nitrite," Carcinogenesis, vol. 8, no. 12, pp. 1843-1845, 1987. 
[113] B. Prokopczyk, A. Rivenson, P. Bertinato, K. D. Brunnemann, and D. Hoffmann, "3-(Methylnitrosamino)propionitrile: occurrence in saliva of betel quid chewers, carcinogenicity, and DNA methylation in F344 rats," Cancer Research, vol. 47, no. 2, pp. 467-471, 1987.

[114] A. Brech, T. Ahlquist, R. A. Lothe, and H. Stenmark, "Autophagy in tumour suppression and promotion," Molecular Oncology, vol. 3, no. 4, pp. 366-375, 2009.

[115] Y.-Q. Tan, J. Zhang, and G. Zhou, "Autophagy and its implication in human oral diseases," Autophagy, vol. 13, no. 2, pp. 225236, 2017.

[116] S. Patil, R. S. Rao, and A. T. Raj, "Dual role of autophagy in oral cancer," Journal of International Oral Health, vol. 7, no. 6, pp. 1-2, 2015.

[117] H.-H. Lu, S.-Y. Kao, T.-Y. Liu et al., "Areca nut extract induced oxidative stress and upregulated hypoxia inducing factor leading to autophagy in oral cancer cells," Autophagy, vol. 6, no. 6, pp. 725-737, 2010.

[118] O. Kujan, K. Shearston, and C. S. Farah, "The role of hypoxia in oral cancer and potentially malignant disorders: a review," Journal of Oral Pathology \& Medicine, vol. 46, no. 4, pp. 246252, 2017.

[119] D. Hanahan and R. A. Weinberg, "The hallmarks of cancer," Cell, vol. 100, no. 1, pp. 57-70, 2000.

[120] D. Hanahan and R. A. Weinberg, "Hallmarks of cancer: the next generation," Cell, vol. 144, no. 5, pp. 646-674, 2011.

[121] L. Feller, M. Altini, and J. Lemmer, "Inflammation in the context of oral cancer," Oral Oncology, vol. 49, no. 9, pp. 887-892, 2013.

[122] S.-W. Park, S.-G. Lee, S.-H. Song et al., "The effect of nitric oxide on cyclooxygenase-2 (COX-2) overexpression in head and neck cancer cell lines," International Journal of Cancer, vol. 107, no. 5, pp. 729-738, 2003.

[123] K. Maaser, P. Däubler, B. Barthel et al., "Oesophageal squamous cell neoplasia in head and neck cancer patients: Upregulation of COX-2 during carcinogenesis," British Journal of Cancer, vol. 88, no. 8, pp. 1217-1222, 2003.

[124] M. Sawhney, N. Rohatgi, J. Kaur et al., "Expression of NF$\kappa \mathrm{B}$ parallels COX-2 expression in oral precancer and cancer: Association with smokeless tobacco," International Journal of Cancer, vol. 120, no. 12, pp. 2545-2556, 2007.

[125] J. H. Jeng, Y. S. Ho, C. P. Chan et al., "Areca nut extract upregulates prostaglandin production, cyclooxygenase- 2 mRNA and protein expression of human oral keratinocytes," Carcinogenesis, vol. 21, no. 7, pp. 1365-1370, 2000.

[126] S. L. Chiang, S. S. Jiang, Y. J. Wang et al., "Characterization of erecoline-induced effects on cytotoxicity in normal human gingival fibroblasts by global gene expression profiling," Toxicological Sciences, vol. 100, no. 1, pp. 66-74, 2007.

[127] P. P. Tak and G. S. Firestein, "NF-kappaB: a key role in inflammatory diseases," The Journal of Clinical Investigation, vol. 107, no. 1, pp. 7-11, 2001.

[128] B. Haefner, "NF-kappa B: arresting a major culprit in cancer," Drug Discovery Therapy, vol. 7, no. 12, pp. 653-663, 2002.

[129] M. Karin, Y. Yamamoto, and Q. M. Wang, "The IKK NF- $\kappa$ B system: a treasure trove for drug development," Nature Reviews Drug Discovery, vol. 3, no. 1, pp. 17-26, 2004.

[130] S.-C. Lin, S.-Y. Lu, S.-Y. Lee, C.-Y. Lin, C.-H. Chen, and K.-W. Chang, "Areca (betel) nut extract activates mitogen-activated protein kinases and NF- $\kappa \mathrm{B}$ in oral keratinocytes," International Journal of Cancer, vol. 116, no. 4, pp. 526-535, 2005.
[131] S.-Y. Lu, K.-W. Chang, C.-J. Liu et al., "Ripe areca nut extract induces G1 phase arrests and senescence-associated phenotypes in normal human oral keratinocyte," Carcinogenesis, vol. 27, no. 6, pp. 1273-1284, 2006.

[132] K. A. Moutasim, V. Jenei, K. Sapienza et al., "Betel-derived alkaloid up-regulates keratinocyte alphavbeta6 integrin expression and promotes oral submucous fibrosis," The Journal of Pathology, vol. 223, no. 3, pp. 366-377, 2011.

[133] W. M. Elshamy and R. J. Duhé, "Overview: cellular plasticity, cancer stem cells and metastasis," Cancer Letters, vol. 341, no. 1, pp. 2-8, 2013.

[134] G. K. Chimal-Ramírez, N. A. Espinoza-Sánchez, and E. M. Fuentes-Pananá, "A role for the inflammatory mediators Cox-2 and metalloproteinases in cancer stemness," Anti-Cancer Agents in Medicinal Chemistry, vol. 15, no. 7, pp. 837-855, 2015.

[135] V. Benegal, R. P. Rajkumar, and K. Muralidharan, "Does areca nut use lead to dependence?" Drug and Alcohol Dependence, vol. 97, no. 1-2, pp. 114-121, 2008.

[136] S. S. Strickland, "Anthropological perspectives on use of the areca nut," Addiction Biology, vol. 7, no. 1, pp. 85-97, 2002.

[137] S. J. Bhat, M. D. Blank, R. L. Balster, and M. Nichter, "Areca nut dependence among chewers in a South Indian community who do not also use tobacco," Addiction, vol. 105, no. 7, pp. 1303-1310, 2010.

[138] A. Dar and S. Khatoon, "Behavioral and biochemical studies of dichloromethane fraction from the Areca catechu nut," Pharmacology Biochemistry \& Behavior, vol. 65, no. 1, pp. 1-6, 2000.

[139] S. Asthana, N. H. Greig, H. W. Holloway et al., "Clinical pharmacokinetics of arecoline in subjects with Alzheimer's disease," Clinical Pharmacology \& Therapeutics, vol. 60, no. 3, pp. 276-282, 1996.

[140] A. Saija, P. Princi, R. De Pasquale, and G. Costa, "Arecoline, but not haloperidol, induces changes in the permeability of the blood-brain barrier in the rat," Journal of Pharmacy and Pharmacology, vol. 42, no. 2, pp. 135-138, 1990.

[141] N.-S. Chu, "Neurological aspects of areca and betel chewing," Addiction Biology, vol. 7, no. 1, pp. 111-114, 2002.

[142] B. G. Burton-Bradley, "Papua and New Guinea transcultural psychiatry: some implications of betel chewing," in Some Aspects of South Pacific Ethnopsychiatry, B. G. Burton-Bradley, Ed., pp. 29-36, South Pacific Commission, Noumea, New Caledonia, 1978.

[143] M. Y. Osman and H. M. Y. Osman, "Inhibitory effect of acetylcholine on monoamine oxidase $\mathrm{A}$ and $\mathrm{B}$ activity in different parts of rat brain," Arzneimittel-Forschung, vol. 58, no. 10, pp. 493-496, 2008.

[144] J. Van Amsterdam, R. Talhout, W. Vleeming, and A. Opperhuizen, "Contribution of monoamine oxidase (MAO) inhibition to tobacco and alcohol addiction," Life Sciences, vol. 79, no. 21, pp. 1969-1973, 2006.

[145] P.-H. Chen, H.-P. Tu, S.-J. Wang et al., "Monoamine oxidase A variants are associated with heavy betel quid use," Addiction Biology, vol. 17, no. 4, pp. 786-797, 2012.

[146] M. D. Berry, A. V. Juorio, and I. A. Paterson, "The functional role of monoamine oxidases A and B in the mammalian central nervous system," Progress in Neurobiology, vol. 42, no. 3, pp. 375-391, 1994.

[147] E. F. McKinney, R. T. Walton, P. Yudkin et al., "Association between polymorphisms in dopamine metabolic enzymes and tobacco consumption in smokers," Pharmacogenetics, vol. 10, no. 6, pp. 483-491, 2000. 
[148] L. Molinengo, M. C. Cassone, and M. Orsetti, "Action of arecoline on the levels of acetylcholine, norepinephrine and dopamine in the mouse central nervous system," Pharmacology Biochemistry \& Behavior, vol. 24, no. 6, pp. 1801-1803, 1986.

[149] K. Y. Zhu, Q. Fu, K. W. Leung, Z. C. F. Wong, R. C. Y. Choi, and K. W. K. Tsim, "The establishment of a sensitive method in determining different neurotransmitters simultaneously in rat brains by using liquid chromatography-electrospray tandem mass spectrometry," Journal of Chromatography B, vol. 879, no. 11-12, pp. 737-742, 2011.

[150] M. T. Bardo and R. A. Bevins, "Conditioned place preference: What does it add to our preclinical understanding of drug reward?” Psychopharmacology, vol. 153, no. 1, pp. 31-43, 2000.

[151] Y. Itzhak, C. Roger-Sánchez, and K. L. Anderson, "Role of the nNOS gene in ethanol-induced conditioned place preference in mice," Alcohol, vol. 43, no. 4, pp. 285-291, 2009.

[152] S. J. Gatley, N. D. Volkow, G.-J. Wang et al., "PET imaging in clinical drug abuse research," Current Pharmaceutical Design, vol. 11, no. 25, pp. 3203-3219, 2005.

[153] C. Leroy, V. Bragulat, I. Berlin et al., "Cerebral monoamine oxidase a inhibition in tobacco smokers confirmed with PET and [11C]befloxatone," Journal of Clinical Psychopharmacology, vol. 29, no. 1, pp. 86-88, 2009.

[154] Y. K. Yang, N. T. Chiu, C. C. Chen, M. Chen, T. L. Yeh, and I. H. Lee, "Correlation between fine motor activity and striatal dopamine D2 receptor density in patients with schizophrenia and healthy controls," Psychiatry Research: Neuroimaging, vol. 123, no. 3, pp. 191-197, 2003.

[155] G. D. Honey, J. Suckling, F. Zelaya et al., "Dopaminergic drug effects on physiological connectivity in a human cortico-striatothalamic system," Brain, vol. 126, part 8, pp. 1767-1781, 2003.

[156] P. C. Hsieh, T. L. Yeh, I. H. Lee et al., "Correlation between errors on the Wisconsin Card Sorting Test and the availability of striatal dopamine transporters in healthy volunteers," Journal of Psychiatry \& Neuroscience, vol. 35, no. 2, pp. 90-94, 2010.

[157] Y. K. Yang, T. L. Yeh, W. J. Yao et al., "Greater availability of dopamine transporters in patients with major depression-a dual-isotope SPECT study," Psychiatry Research: Neuroimaging, vol. 162, no. 3, pp. 230-235, 2008.

[158] T. L. Yeh, I. H. Lee, P. S. Chen et al., "Social support and striatal dopaminergic activities: Is there a connection?" Progress in Neuro-Psychopharmacology \& Biological Psychiatry, vol. 33, no. 7, pp. 1141-1146, 2009.

[159] P.-H. Chen, B. Huang, T.-Y. Shieh et al., "The influence of monoamine oxidase variants on the risk of betel quidassociated oral and pharyngeal cancer," The Scientific World Journal, vol. 2014, Article ID 183548, 8 pages, 2014. 

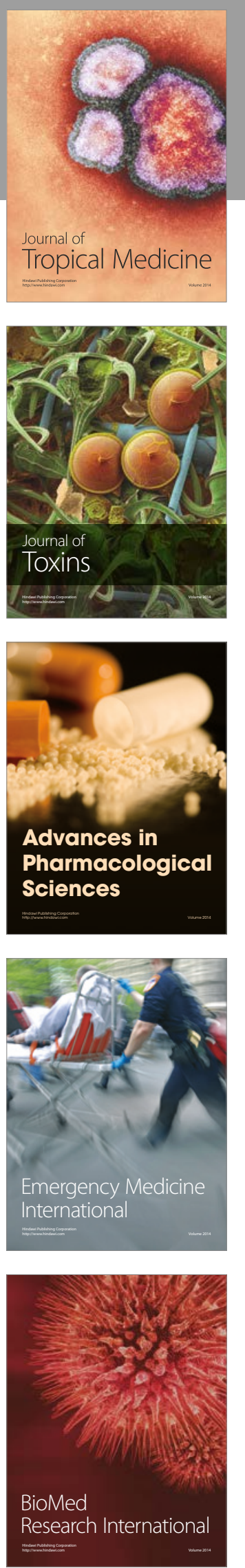
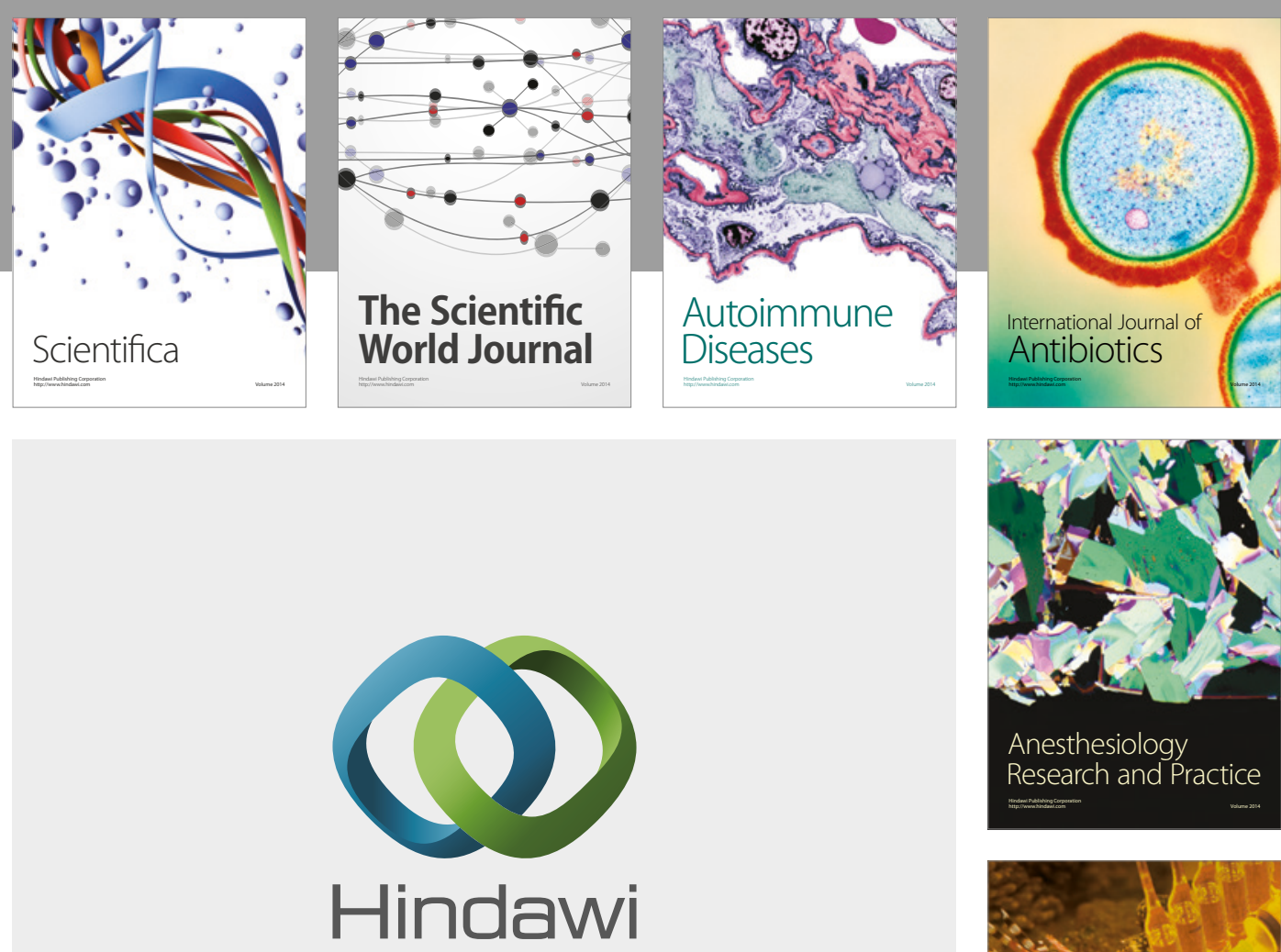

Submit your manuscripts at

https://www.hindawi.com
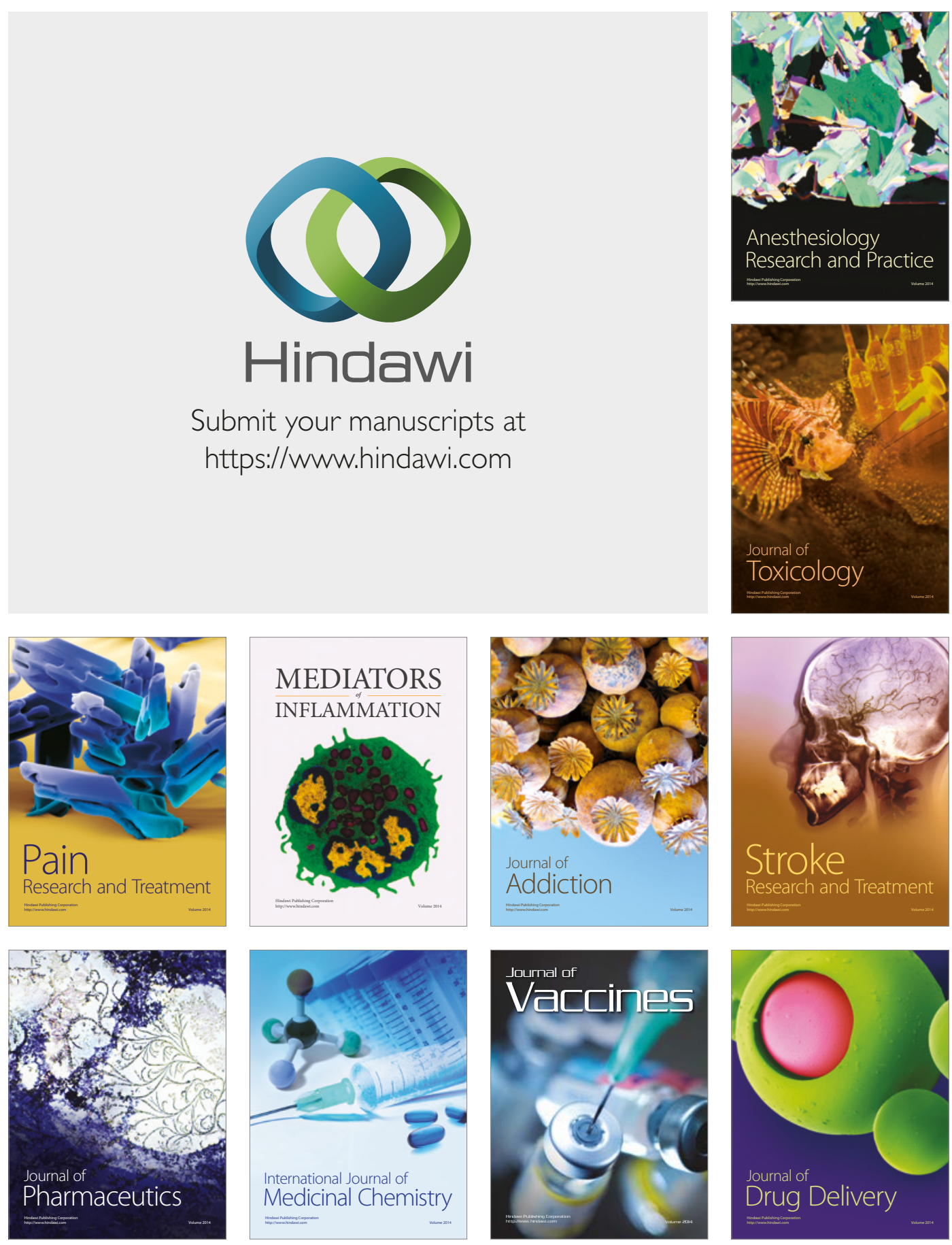